\title{
Insights into the ground attachment process of natural lightning gained from an unusual triggered-lightning stroke
}

\author{
J. Jerauld, ${ }^{1}$ M. A. Uman, ${ }^{1}$ V. A. Rakov, ${ }^{1}$ K. J. Rambo, ${ }^{1}$ and G. H. Schnetzer ${ }^{1}$ \\ Received 19 June 2006; revised 29 January 2007; accepted 17 April 2007; published 7 July 2007.
}

[1] We present measured electric and magnetic field and current derivatives from an unusual triggered-lightning stroke that was initiated by a dart-stepped leader and that involved an upward connecting leader. The initial rising portion of the current (integrated $\mathrm{d} I / \mathrm{d} t$ ) waveform is composed of a "slow front" rising to $20 \mathrm{kA}$ in $2.2 \mu \mathrm{s}$, followed by a "fast transition" from 20 to $27 \mathrm{kA}$ in $0.2 \mu \mathrm{s}$. A similar slow-front/fast-transition sequence has been observed in the currents and in the distant radiation fields of natural-lightning first strokes. Field derivatives measured at 15 and $30 \mathrm{~m}$ for the triggered-lightning stroke are similar to those measured for natural-lightning first strokes occurring within a few hundred meters. Two versions of the transmission line model, with the measured current derivative and assumed propagation speeds as input, are able to reasonably reproduce the slow fronts and fast transitions in the field derivatives measured at 15 and $30 \mathrm{~m}$ (the electric field slow front being primarily electrostatic) and predict the slow front in the distant radiation fields. These results suggest that the source of the slow fronts observed in the currents and in the distant radiation fields of natural first strokes is likely to be a pair of microsecond-scale current waves, each having a peak of up to some tens of kiloamperes, propagating in opposite directions from the junction of the descending and upward connecting leaders at a speed on the order of $10^{8} \mathrm{~m} \mathrm{~s}^{-1}$, rather than the upward connecting leader itself, as is often thought.

Citation: Jerauld, J., M. A. Uman, V. A. Rakov, K. J. Rambo, and G. H. Schnetzer (2007), Insights into the ground attachment process of natural lightning gained from an unusual triggered-lightning stroke, J. Geophys. Res., 112, D13113, doi:10.1029/2006JD007682.

\section{Introduction}

[2] Currents of return strokes in downward natural negative lightning, including first return strokes, have been measured on towers by, for example, Berger et al. [1975] in Switzerland, Eriksson [1978] in South Africa, and Visacro et al. [2004] in Brazil. Many studies have been conducted to examine first-stroke electric fields in the range of 1 to over $100 \mathrm{~km}$ from the lightning discharge, including those of Lin et al. [1979] in Florida, Weidman and Krider [1978] in Florida and Arizona, and Cooray and Lundquist [1982] in Sweden. The initial rising portion of both firststroke current waveforms and distant first-stroke electric and magnetic field waveforms can be separated into two phases, the first being the so-called "initial slow front," or simply "slow front," observed by Weidman and Krider [1978] for distant fields to rise for $2-8 \mu$ s to about half the field peak. The field slow front is followed by an abrupt transition to peak, typically referred to as the "fast transition," having a $10-90 \%$ risetime of $0.2 \mu$ s or less when the field propagation was over seawater, according to Weidman and Krider [1978] (Weidman and Krider [1980] give a 10-

\footnotetext{
${ }^{1}$ Department of Electrical and Computer Engineering, University of Florida, Gainesville, Florida, USA.

Copyright 2007 by the American Geophysical Union. 0148-0227/07/2006JD007682\$09.00
}

$90 \%$ risetime of $0.1 \mu$ s over seawater). There are no detailed statistics on the slow front and fast transition of the firststroke current similar to those reported by Weidman and Krider [1978] for distant fields although Anderson and Eriksson [1980], using the data of Berger et al. [1975], reported a median overall first-stroke current front duration (which includes both the slow front and the fast transition) of 3.8-5.6 $\mu \mathrm{s}$, depending on the estimation method. The shape of the slow front is typically concave in both measured currents and distant fields although Weidman and Krider [1978] do report some convex-shaped slowfront fields. The average ratio of the amplitude of the slow front to the total peak field for 152 first-stroke electric fields that propagated over seawater is reported by Weidman and Krider [1978] to be $0.4-0.5$ with an average duration of $4 \mu$ s. Cooray and Lundquist [1982] and Master et al. [1984] give average ratios of about 0.4 and 0.3 and average durations of 5 and $2.9 \mu \mathrm{s}$, respectively. The average fasttransition 10-90\% risetime observed by Master et al. [1984] is about an order of magnitude larger than that reported by Weidman and Krider [1980] due to the field propagation over 1 to $20 \mathrm{~km}$ of land in the former's study. Willett and Krider [2000], for 76 distant first-stroke electric fields and field derivatives propagating over seawater, report an average slow-front duration of $3.7 \pm 1.2 \mu \mathrm{s}$ and an average amplitude of $50 \pm 10 \%$ relative to the peak field. Furthermore, Willett and Krider [2000] found the latter ratio 
to be uncorrelated with either the peak electric field or peak $\mathrm{d} E / \mathrm{d} t$. Interestingly, from the high-time-resolution (10 ns) distant fields reported by Murray et al. [2005], it is not clear if there really is a distinct demarcation between the slow front and the fast transition.

[3] Weidman and Krider [1978] report that subsequent strokes initiated by dart leaders also exhibit slow fronts and fast transitions in their distant fields but that the slow fronts are generally both smaller in amplitude, with the mean front amplitude to total field peak ratio for 164 subsequent strokes being about 0.2 , and shorter in duration, a mean of $0.6-0.9 \mu \mathrm{s}$, than those of first strokes. Significantly, the fast transition of subsequent strokes initiated by dart leaders is similar in both average amplitude and average duration to that of first strokes, indicating that the primary distinction between first and subsequent stroke fields is the slow front. The total front duration reported by Anderson and Eriksson [1980] for subsequent stroke currents is 0.6$0.8 \mu \mathrm{s}$, depending on the estimation method. Finally, Weidman and Krider [1978] found that the slow fronts from 34 subsequent strokes initiated by dart-stepped leaders had an average front amplitude to peak field ratio similar to that of first strokes, but a mean duration of $2.1 \mu \mathrm{s}$, between those of first (mean of $4 \mu \mathrm{s}$ ) and subsequent strokes initiated by dart leaders (mean of $0.6-0.9 \mu \mathrm{s}$ ).

[4] There is no clear physical understanding of how natural-lightning first-stroke currents measured at the channel base are related to the distant fields, although several return-stroke models have been found to produce reasonable results in relating the two in the case of subsequent strokes [e.g., Rakov and Uman, 1998]. Specifically, the transmission line (TL) model [Uman and McLain, 1969] has been demonstrated to work reasonably well in reproducing both close [e.g., Schoene et al., 2003] and relatively distant [e.g., Willett et al., 1988] fields for the first few microseconds of strokes in rocket-triggered lightning (which are thought to be similar to natural negative lightning subsequent strokes).

[5] The origin of the slow-front current in first strokes has long been a matter of discussion. It has often been attributed to the presence of an upward connecting leader [e.g., Rakov and Uman, 2003, p. 144]. Weidman and Krider [1978] noted that "the shapes and relative amplitudes of the fronts and fast transitions in the current waveforms are surprisingly similar to those in the radiated fields" (currents and fields being measured in different studies), perhaps indicating that the TL model, with the overall current waveforms starting at ground level and propagating upward, might be applicable to computing both the slow front and fast transition of natural-lightning first-stroke fields. On the other hand, there are experimental data [Willett et al., 1989a, p. 13,283], although for triggered-lightning strokes, which suggest that radiation field waveforms can exhibit pronounced slow fronts without similar features in corresponding current waveforms. Other models of slow-front production have been considered by Weidman and Krider [1978], Thottappillil and Uman [1993], and Cooray et al. [2004].

[6] In the present paper, we show that both close and distant fields can be predicted by a version of the TL model in which both the slow-front and fast-transition currents are generated at the junction point of the upward and downward leaders and propagate away from that point, a model that is more physically reasonable than the model assuming that the current is generated at ground level. We provide support to this view with data from an unusual triggered-lightning stroke, having characteristics that appear to be remarkably similar to negative natural-lightning first strokes, as well as with previously reported current, electric field, and optical observations of both natural and triggered lightning.

\section{Experiment}

\subsection{Rocket-Triggered Lightning Experiment}

[7] The triggered-lightning experiment reported here was conducted in 2001 at the International Center for Lightning Research and Testing (ICLRT) at Camp Blanding, Florida. Lightning channels terminated on a $4.5-\mathrm{m}$ vertical section of natural-gas pipeline (consisting of three different metallic sections connected by insulating joints), henceforth referred to as the strike object, as part of an experiment to test the lightning susceptibility of the pipeline. Rockets trailing thin grounded wires were launched from an underground launcher, and current was measured at the base of the strike object using a resistive shunt having a resistance of $1 \mathrm{~m} \Omega$. Current waveforms were transmitted to the metallic SATTLIF trailer using a Nicolet Isobe 3000 fiber-optic link. Rocket launching operations and data acquisition took place within the SATTLIF trailer. In addition, current derivative $(\mathrm{d} I / \mathrm{d} t)$ was measured by an EG\&G IMM-5 I-Dot sensor surrounding the base of the strike object and transmitted to the SATTLIF trailer using a Nanofast fiber-optic link. The IMM-5 sensor and Nanofast fiber-optic link have, for each of them, a bandwidth of some hundreds of megahertz, but the high-frequency response was limited to $20 \mathrm{MHz}$ by an external passive low-pass filter at the output of the fiberoptic link. The low-frequency limit of the $\mathrm{d} I / \mathrm{d} t$ measurement was about $70 \mathrm{~Hz}$, the low-frequency limit of the Nanofast link. The strike object was attached to the underground launcher located in the center of and bonded to a $70 \times 70-\mathrm{m}$ buried metallic mesh (ground plane) having a DC grounding resistance of about $8 \Omega$. Electric and magnetic field derivatives $(\mathrm{d} E / \mathrm{d} t$ and $\mathrm{d} B / \mathrm{d} t$, respectively) were measured at distances of 15 and $30 \mathrm{~m}$ from the strike object in the southwest quadrant of the ground plane, and the $\mathrm{d} E / \mathrm{d} t$ and $\mathrm{d} B / \mathrm{d} t$ sensors at each distance were separated in azimuth by about $15^{\circ}$. The vertical component of $\mathrm{d} E / \mathrm{d} t$ was measured with circular flat-plate antennas having an area of about $0.155 \mathrm{~m}^{2}$ and mounted flush with the ground, and the horizontal component of $\mathrm{d} B / \mathrm{d} t$ was measured with vertical loops of $50 \Omega$ coaxial cable having an area of about $0.11 \mathrm{~m}^{2}$. Electronics for the field derivative measurements were housed in metal enclosures, and the resultant waveforms were transmitted over Meret fiber-optic links to the SATTLIF trailer where they were low-pass-filtered at $20 \mathrm{MHz}$ and were digitized along with the current and $\mathrm{d} I / \mathrm{d} t$ measurements. $\mathrm{d} I / \mathrm{d} t, \mathrm{~d} B / \mathrm{d} t$ at $15 \mathrm{~m}$, and $\mathrm{d} E / \mathrm{d} t$ at 15 and $30 \mathrm{~m}$ were recorded together on a four-channel LeCroy 9354 8-bit digital storage oscilloscope operating in segmented memory mode $(10 \mu$ s per segment with $50 \%$ pretrigger) and sampling at $250 \mathrm{MHz}$. Directly measured current and $\mathrm{d} B / \mathrm{d} t$ at $30 \mathrm{~m}$ were recorded on separate LeCroy 9400A oscilloscopes sampling at 25 and $50 \mathrm{MHz}$, respectively. 
[8] The trigger for the oscilloscopes was derived from the directly measured current. Details of the experimental configuration, including measurements not discussed here, are found in the studies of Schoene et al. [2003] and Kodali et al. [2005]. Color and monochrome CCD video cameras were situated on top of the SATTLIF trailer, west of the launcher. Video signals were transferred via fiberoptic links to the trailer where they were recorded on SVHS tape. Stand-alone 8-mm video cameras were placed at the north and southeast edges of the ground plane. Furthermore, a high-speed 16-mm camera operated at 200 frames per second ( $1 \mathrm{~ms}$ exposure per frame) viewed the triggered lightning from within SATTLIF. The video records were digitized on a PC at a resolution of $720 \times 480$ pixels, and individual frames from the $16-\mathrm{mm}$ framing camera were scanned at 3200 dots per inch with 24-bit color. A Pentax SG-10 35-mm SLR camera was also located on the roof of the trailer and was set to automatically acquire a 6-s exposure when each rocket was fired.

\subsection{Natural Lightning Experiment}

[9] The multiple-station field-measuring experiment (MSE), data from which are presented here, was designed to acquire close (within a few hundred meters) electric and magnetic field and field-derivative waveforms from an expected five to eight natural lightning flashes per year. The network covers an area of approximately $0.5 \mathrm{~km}^{2}$ and, from 2002 to 2005, was comprised of six electric field measurements, two magnetic field measurements, four $\mathrm{d} E / \mathrm{d} t$ measurements, four $\mathrm{d} B / \mathrm{d} t$ measurements, and two optical measurements. Waveforms were transmitted over Opticomm MMV-120C fiber-optic links to the shielded Launch Control trailer, where they were filtered and digitized. The output of a field mill (measuring the quasi-static electric field at ground, which can be used as an indicator of thunderstorm conditions) was monitored by a PC which automatically armed and disarmed the experiment when conditions were appropriate. The digitizers were triggered when the output of the two optical sensors (viewing the network from its opposite corners) simultaneously exceeded a threshold, so that data were obtained only for lightning within or very near the network. In this paper, only $\mathrm{d} E / \mathrm{d} t$ measurements for natural lightning are presented. These waveforms were sensed with flat-plate antennas similar to those discussed in section 2.1. The $\mathrm{d} E / \mathrm{d} t$ waveforms were low-pass-filtered at $20 \mathrm{MHz}$ and were digitized on an 8-bit LeCroy LT374 oscilloscope operating in segmented memory mode (5 ms per segment with $80 \%$ pretrigger) and sampling at $200 \mathrm{MHz}$. More details of the experiment can be found in the paper of Jerauld et al. [2003].

\section{Data Presentation and Comparison}

\subsection{Triggered Lightning}

[10] Flash S0123 was triggered on 18 August 2001 at approximately 23:44 UT. The flash consisted of an initial stage (upward positive leader, explosion of the triggering wire, its replacement with a plasma channel, and subsequent steady current flow [Rakov et al., 2003; Miki et al., 2005]) followed by five leader/return-stroke sequences, all effectively lowering negative charge to ground, with each stroke attaching to the top of the $4.5-\mathrm{m}$ strike object. Strokes 3, 4,

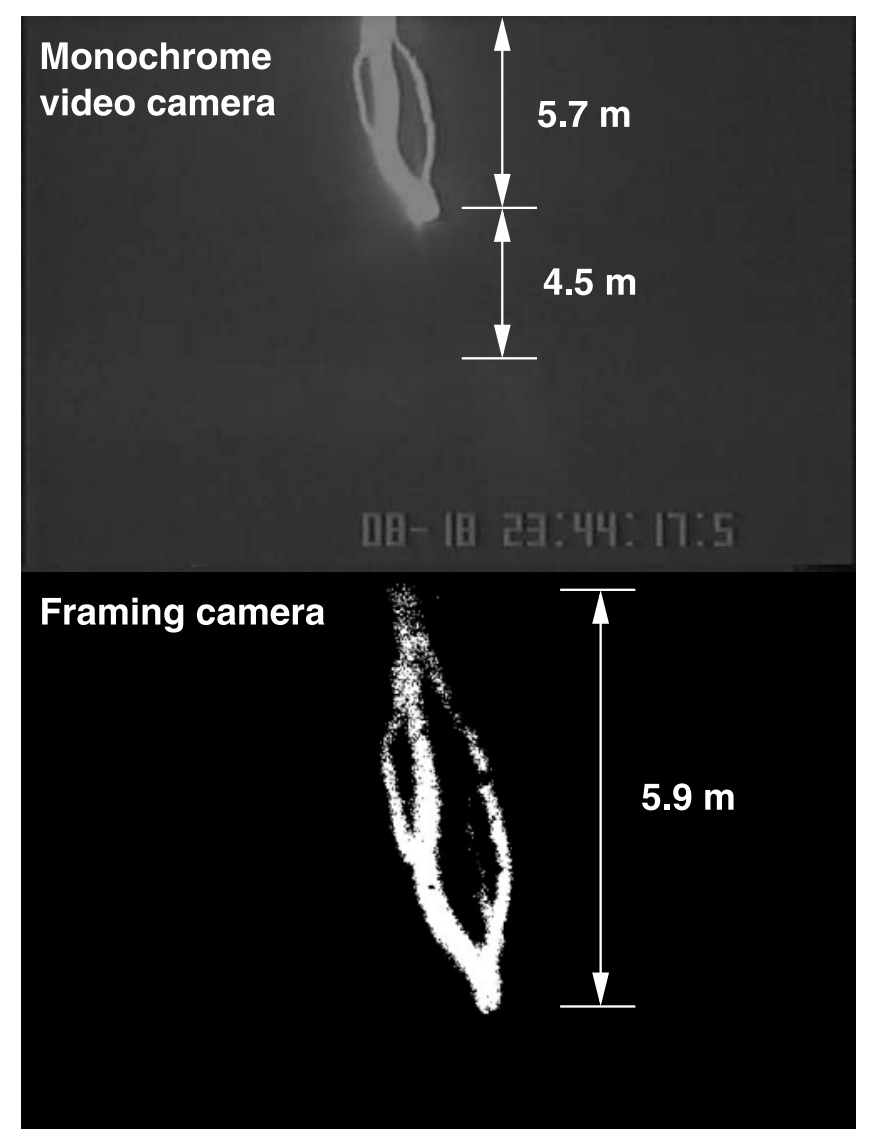

Figure 1. Monochrome video frame (top) and framing camera image (bottom) recorded from the SATTLIF trailer for stroke 3 of triggered-lightning flash S0123. The framing camera image has been thresholded for enhancement. Estimated heights are labeled on each image.

and 5 were apparently preceded by dart-stepped leaders as inferred from the measured field and field-derivative waveforms. Stroke 3 is the focus of this paper because the characteristics of its fields and field derivatives appear to be remarkably similar to those of natural negative first return strokes. Stroke 3 followed stroke 2 after about $467 \mathrm{~ms}$ (an unusually long interstroke interval), with stroke 4 following stroke 3 about $112 \mathrm{~ms}$ later. Stroke 3 was the only stroke in the flash whose current began with a significant slow front.

[11] Figure 1 shows a video frame from the monochrome CCD camera, along with a framing camera image, both recorded from the SATTLIF trailer (west of the launcher), for the third stroke of the flash. The framing camera image was thresholded (pixels above a certain intensity are set white with the remainder set black) because it was severely washed out and multiple reflections (from the window) were present obscuring the image. Although not obvious from the two-dimensional views of Figure 1, the lowest $8 \mathrm{~m}$ of the channel (not including the strike object) leans to the west (toward the camera in the images of Figure 1) at an angle of about $40^{\circ}$. Some minor tortuosity is observed above this channel section, after which the channel is mostly straight and vertical. Both images in Figure 1 show three distinct channel segments, forming what appear to be 

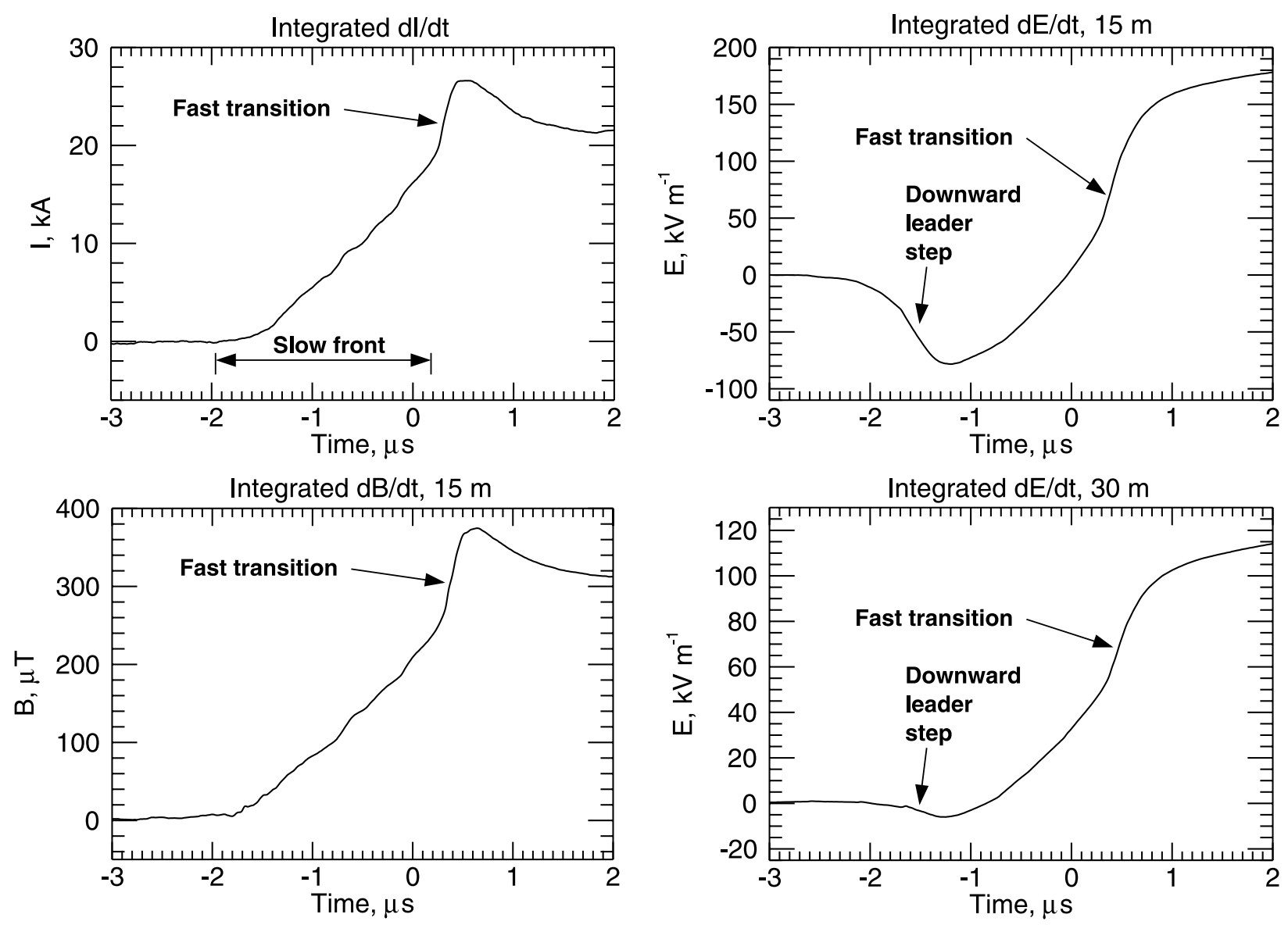

Figure 2. Numerically integrated $\mathrm{d} I / \mathrm{d} t, \mathrm{~d} B / \mathrm{d} t$ at $15 \mathrm{~m}$, and $\mathrm{d} E / \mathrm{d} t$ at 15 and $30 \mathrm{~m}$ waveforms for stroke 3 of triggered-lightning flash S0123. Positive current indicates positive charge moving upward (negative charge lowered to ground), and the electric field polarity is consistent with the atmospheric electricity sign convention. Time zero indicates the trigger point of the digitizer.

two loops. This phenomenon has a duration of less than a single framing-camera interval $(5 \mathrm{~ms})$, as only the middle channel segment is present in subsequent frames from this stroke. The channel loops are also present in other video records of this event although not nearly as clearly. Furthermore, they are seen in the still image although only the bottom half was imaged and it was partially obscured by the initial stage of the triggered lightning and other return strokes. The channel images shown in Figure 1 are similar to those described by Hagenguth [1947] and Golde [1967]. The former was a natural strike to a patch of weeds in a lake where the channel was split between about 3 and $9 \mathrm{~m}$ above the water, and the latter was a natural strike to a chimney where at least three separate loop-forming channel segments were observed about $9 \mathrm{~m}$ above the chimney top. On the basis of time-resolved images from long-spark experiments, these loops have been interpreted to indicate the connection region of the upward and downward leaders. If that interpretation is used for the triggered-lightning stroke discussed here, then the attachment occurred within the bottom few meters of the channel (which leans about $40^{\circ}$ to the west) above the 4.5-m strike object, with the upward connecting leader having at most a length of a few meters.
[12] In addition to the channel loops, at least two unconnected upward discharges (not seen in Figure 1) are observed to extend upward from the tip of the strike object, the longest being about $4 \mathrm{~m}$. It is interesting to note that Rakov and Uman [2003, pp. 142-143] infer from photographs published by Krider and Ladd [1975] that the presence of unconnected upward discharges in the immediate vicinity of the strike point suggests that an upward connecting leader of greater length than the unconnected discharges must have been involved in the attachment process. If that inference is applied to the triggered-lightning stroke discussed here, the upward connecting leader involved in the attachment process must be longer than $4 \mathrm{~m}$ although this reasoning may not be strictly applicable since the upward connecting discharge is leaning about $40^{\circ}$ to the west while the unconnected discharges appear to be mostly vertical.

[13] Figure 2 shows numerically integrated measured waveforms of $\mathrm{d} I / \mathrm{d} t, \mathrm{~d} B / \mathrm{d} t$ at $15 \mathrm{~m}$, and $\mathrm{d} E / \mathrm{d} t$ at 15 and $30 \mathrm{~m}$ for stroke 3 of the flash. Figure 3 shows the measured $\mathrm{d} I / \mathrm{d} t$ and field derivatives from which Figure 2 was derived. These four waveforms were chosen for presentation because they were recorded on the same four-channel LeCroy 9354 digitizer, sampling at $250 \mathrm{MHz}$, and contain the highest time precision and least trigger ambiguity of all the wave- 

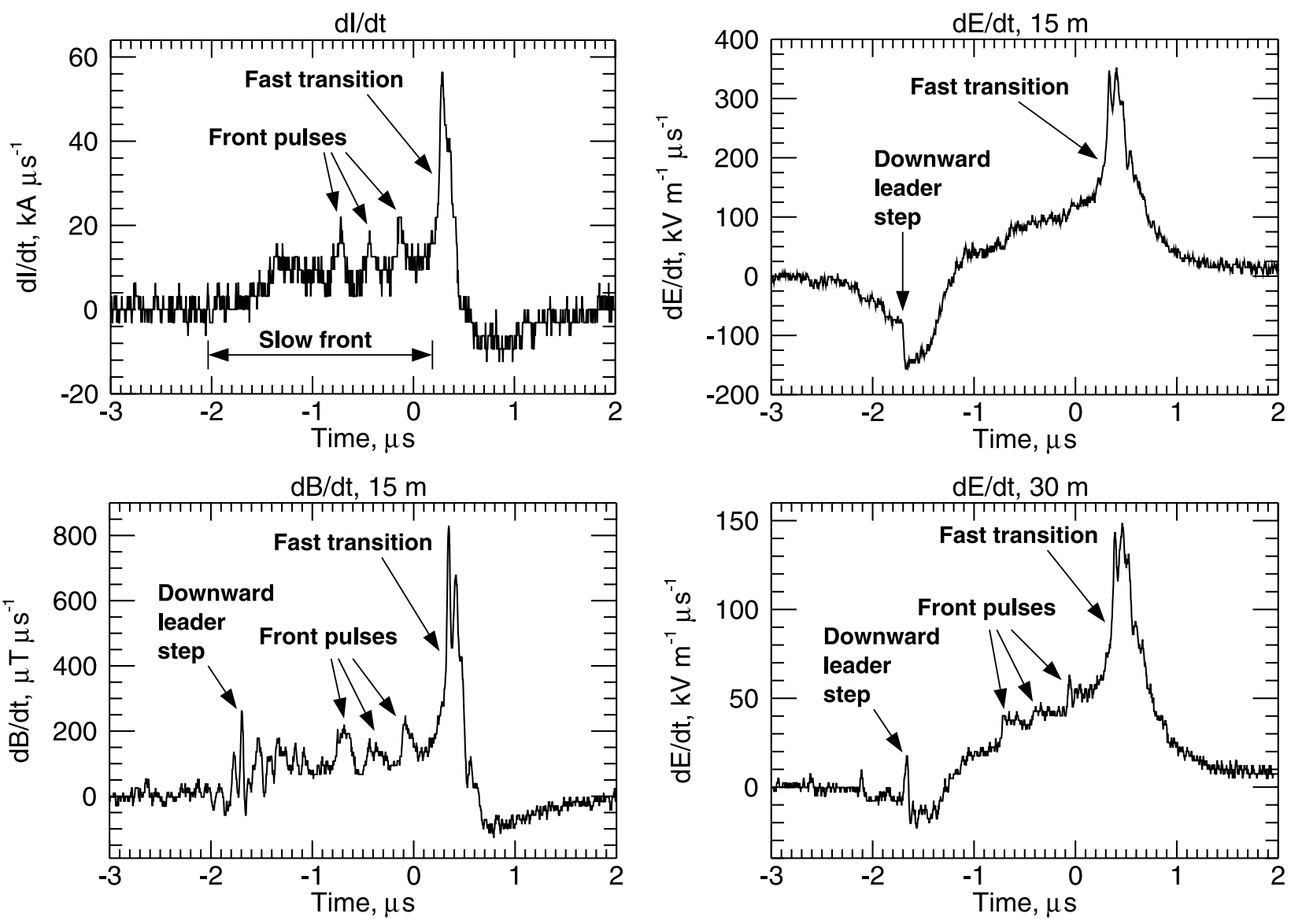

Figure 3. $\mathrm{d} I / \mathrm{d} t, \mathrm{~d} B / \mathrm{d} t$ at $15 \mathrm{~m}$, and $\mathrm{d} E / \mathrm{d} t$ at 15 and $30 \mathrm{~m}$ waveforms for stroke 3 of triggered-lightning flash S0123. Positive current indicates positive charge moving upward (negative charge lowered to ground), and the $\mathrm{d} E / \mathrm{d} t$ polarity is consistent with the atmospheric electricity sign convention. Time zero indicates the trigger point of the digitizer.

forms recorded. The integrated $\mathrm{d} I / \mathrm{d} t$ waveform of Figure 2 is comprised of a slow front, rising to about $20 \mathrm{kA}$ in about $2.2 \mu \mathrm{s}$, followed by a fast transition, rising to a peak of about $27 \mathrm{kA}$ in about $0.2 \mu \mathrm{s}$. This slow front is similar to those observed for natural-lightning first-stroke currents measured on tall towers [e.g., Berger et al., 1975 in Switzerland, Eriksson, 1978 in South Africa, and Visacro et al., 2004 in Brazil] and for distant first-stroke electric and magnetic radiation fields [e.g., Weidman and Krider, 1978 in Florida and Arizona and Cooray and Lundquist, 1982 in Sweden]. For our event, using integrated $\mathrm{d} I / \mathrm{d} t$, the slow front amplitude to total peak ratio of the current is about 0.74 (about 0.70 for directly measured current), which is larger than the mean of $0.4-0.5$ given by Weidman and Krider [1978] for distant natural-lightning first-stroke electric fields, but still within their statistical distribution (less than 0.1 to greater than 0.8 ). As noted in section 1 , Weidman and Krider [1978] also observed that slow-front amplitudes relative to total peak field for strokes believed to be preceded by dart-stepped leaders are similar to those of first strokes (mean of 0.4 ), with a mean duration of $2.1 \mu \mathrm{s}$, the latter value being similar to that for the triggeredlightning stroke described here $(2.2 \mu \mathrm{s})$. Slow fronts in both directly measured first-stroke currents and radiation fields are typically concave in shape, while the slow front in the current waveform of the triggered-lightning stroke discussed here appears to be quasi-linear. However, there appears to be some positive slope in the slow front of the $\mathrm{d} I / \mathrm{d} t$ waveform, indicating that the slow front in the current (integrated $\mathrm{d} I / \mathrm{d} t$ ) is actually slightly concave.

[14] We note that while the slow-front waveforms for integrated $\mathrm{d} I / \mathrm{d} t$ and directly measured current (not shown) agree well, the match is not as good for the fast transitions to peak that follow the slow fronts, with the directly measured current having an overall peak of about $29 \mathrm{kA}$. The reason for this discrepancy is unknown, but it is unlikely to be due to the frequency response of the $\mathrm{d} I / \mathrm{d} t$ measurement (approximately $70 \mathrm{~Hz}-20 \mathrm{MHz}$, as discussed in section 2).

[15] The integrated $\mathrm{d} B / \mathrm{d} t$ (magnetic field) waveform in Figure 2, measured at $15 \mathrm{~m}$, is very similar to the integrated $\mathrm{d} I / \mathrm{d} t$ waveform. While the shapes of the slow fronts in both the integrated $\mathrm{d} I / \mathrm{d} t$ and the integrated $\mathrm{d} B / \mathrm{d} t$ waveforms are quasi-linear, the corresponding slow-front integrated $\mathrm{d} E / \mathrm{d} t$ (electric field) waveforms observed at 15 and $30 \mathrm{~m}$ are more concave. The integrated $\mathrm{d} E / \mathrm{d} t$ waveforms also show the signature of the final downward leader step, as indicated in Figure 2. No step signature is observed in the integrated $\mathrm{d} B / \mathrm{d} t$ waveform. This is probably because, according to our modeling, an elevated, approximately vertical, current source, such as a leader step (probably a few meters or more 

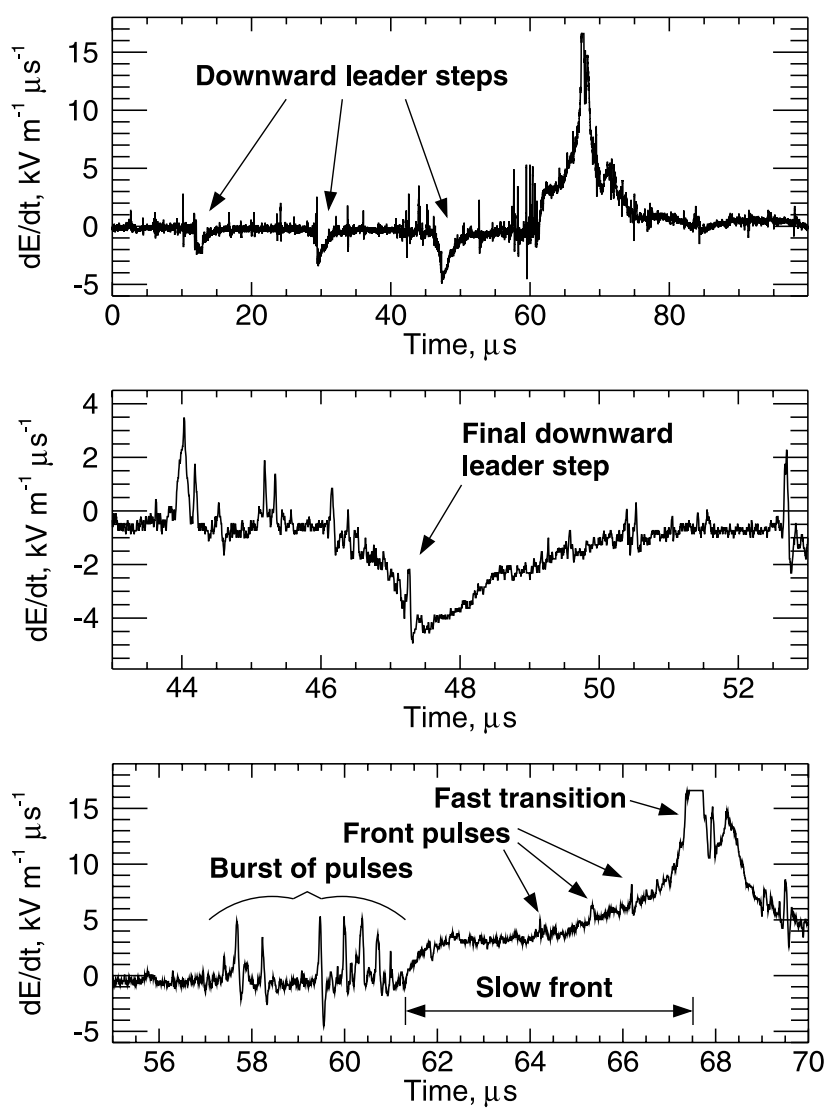

Figure 4. Natural negative lightning first-stroke $\mathrm{d} E / \mathrm{d} t$ waveforms measured approximately $160 \mathrm{~m}$ from the channel. The middle and bottom plots show zooms of the final leader step and slow front, respectively. The $\mathrm{d} E / \mathrm{d} t$ polarity is consistent with the atmospheric electricity sign convention. Note that the fast-transition peak is saturated.

above the 4.5-m strike object in this case), produces a relatively small (compared with the following return stroke) magnetic field at ground level at close horizontal distances.

[16] The $\mathrm{d} I / \mathrm{d} t$ and field derivative waveforms of Figure 3 show much more fine structure than their integrated counterparts in Figure 2. All derivative waveforms, with the exception of $\mathrm{d} E / \mathrm{d} t$ at $15 \mathrm{~m}$, clearly show three similar pulses occurring during the slow front. These pulses are likely also present in the $15-\mathrm{m} \mathrm{d} E / \mathrm{d} t$ waveform since they are observed in the corresponding $\mathrm{d} B / \mathrm{d} t$ waveform, but their amplitudes are probably below the noise level. Interestingly, the downward leader-step $\mathrm{d} E / \mathrm{d} t$ signatures at 15 and $30 \mathrm{~m}$ are markedly different. Whereas the $15-\mathrm{m}$ downward leaderstep $\mathrm{d} E / \mathrm{d} t$ waveform is comprised of several small negative transitions superimposed on a monotonically decreasing waveform, followed by a larger negative transition at about $-1.7 \mu \mathrm{s}$, the $30-\mathrm{m}$ waveform is comprised of (what appear to be) unipolar pulses (each having a width on the order of $50 \mathrm{~ns}$ ) superimposed on a monotonically decreasing waveform. The corresponding $\mathrm{d} B / \mathrm{d} t$ downward leader-step signature is a seemingly chaotic sequence of pulses although the largest pulse does correspond to the large negative transition in the $15-\mathrm{m} \mathrm{d} E / \mathrm{d} t$ leader-step waveform and the large positive pulse in the $30-\mathrm{m} \mathrm{d} E / \mathrm{d} t$ leader-step waveform.
We also note that the beginning of the slow front (determined to be about time $-2 \mu$ s based on the $\mathrm{d} I / \mathrm{d} t$ waveform as indicated in Figures 2 and 3) occurs during the final leader-step prior to the dominant negative transition in the $15-\mathrm{m} \mathrm{d} E / \mathrm{d} t$ leader-step waveform and the dominant pulse in the $15-\mathrm{m} \mathrm{d} B / \mathrm{d} t$ and $30-\mathrm{m} \mathrm{d} E / \mathrm{d} t$ leader-step waveforms. Thus we believe the first microsecond or so of the field and field-derivative waveforms shown in Figures 2 and 3 to be the superposition of the fields from the downward leader step and the beginning of the slow front. Finally, all of the field derivatives exhibit a double peak (separation of about $70 \mathrm{~ns}$ ) during the fast transition, which is most pronounced in the $15-\mathrm{m} \mathrm{d} B / \mathrm{d} t$ waveform. There is no corresponding double peak in the $\mathrm{d} I / \mathrm{d} t$ waveform although there is a shoulder observed about 70 ns after the peak, which may be related to the double peaks observed in the field-derivative waveforms.

\subsection{Natural Lightning}

[17] We have observed slow fronts in close natural firststroke fields and field derivatives recorded by the MSE, such as the event shown in Figures 4 and 5 . The $\mathrm{d} E / \mathrm{d} t$ waveform of Figure 4 (and its numerically integrated version
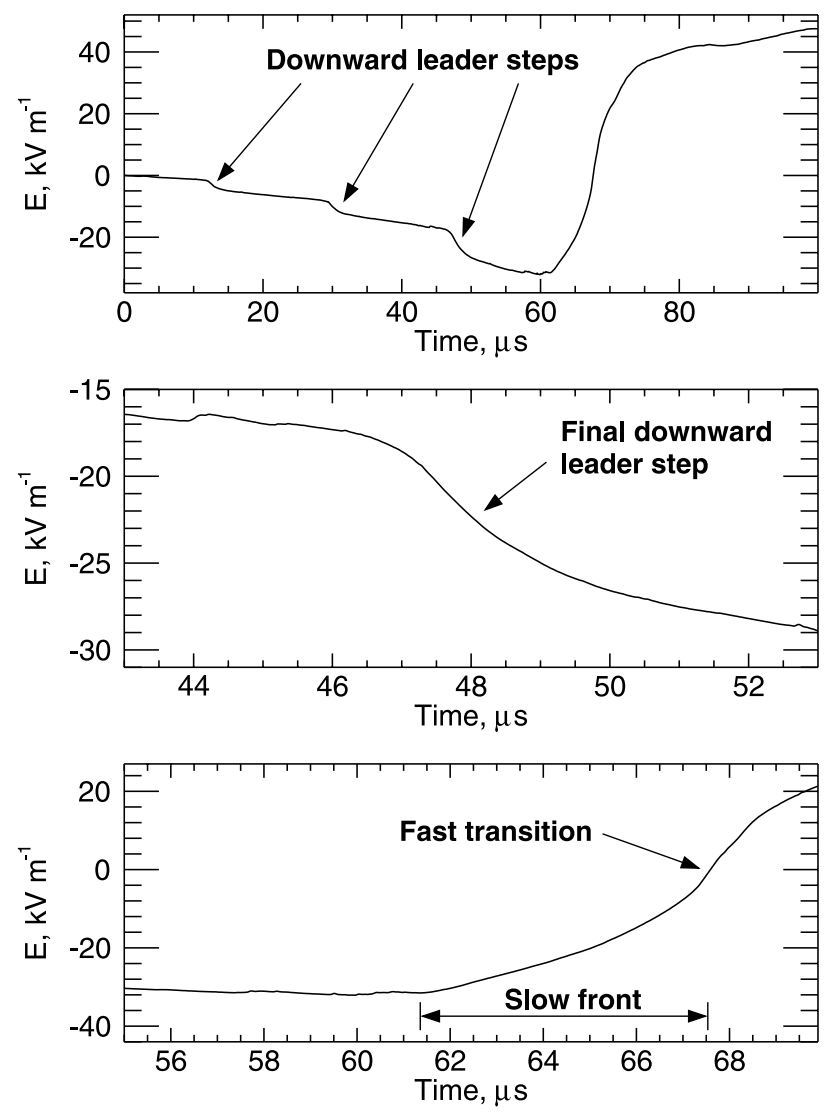

Figure 5. Numerically integrated versions of the firststroke $\mathrm{d} E / \mathrm{d} t$ waveforms (measured about $130 \mathrm{~m}$ from the channel) presented in Figure 4. The middle and bottom plots show zooms of the final leader step and slow front, respectively. Electric field polarity is consistent with the atmospheric electricity sign convention. Note the $\mathrm{d} E / \mathrm{d} t$ peak saturates at time $67.4 \mu \mathrm{s}$, thus the integrated waveform should be considered distorted after that time. 

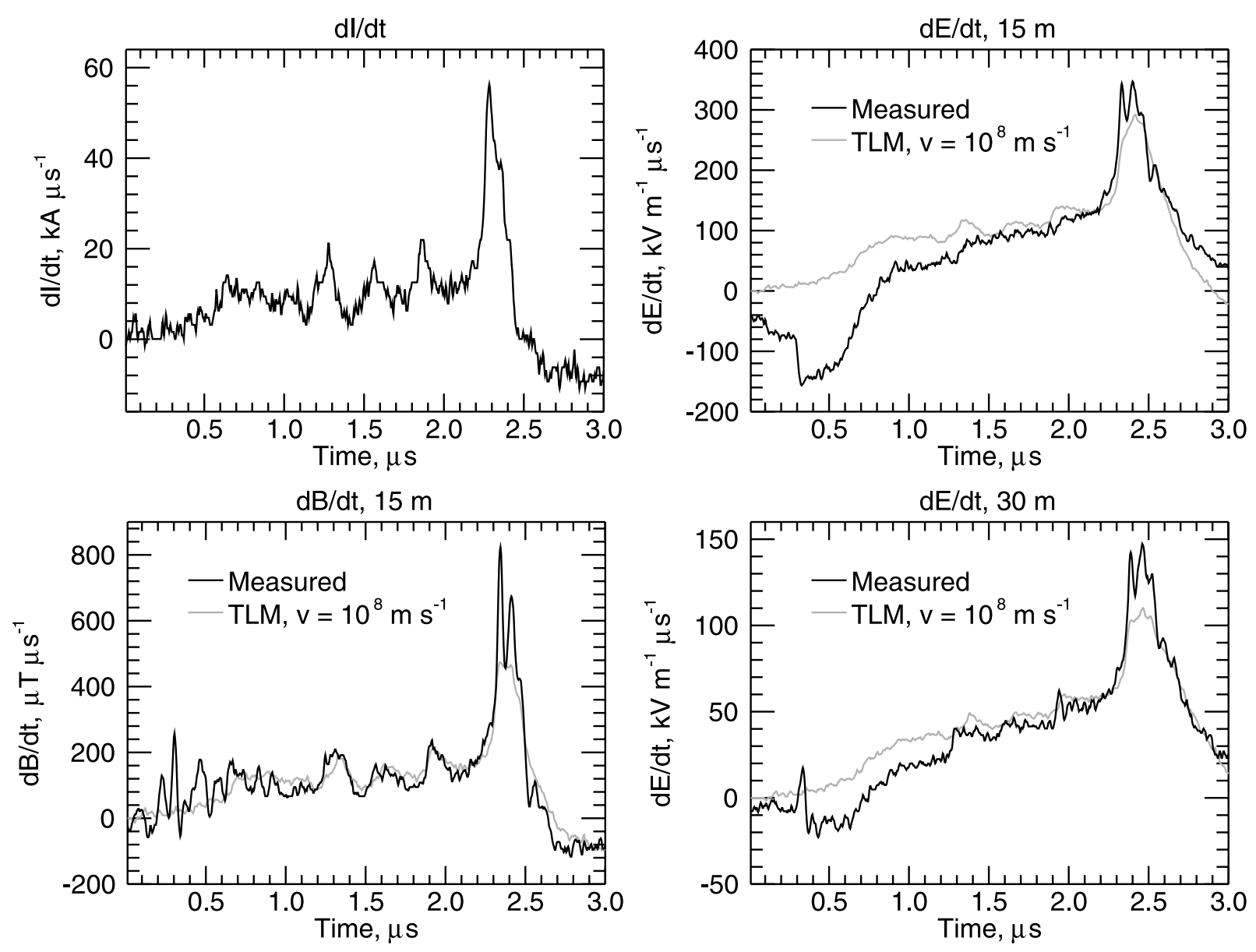

Figure 6. Field derivatives calculated using the single-wave transmission line model (TLM) at a speed of $10^{8} \mathrm{~m} \mathrm{~s}^{-1}$ with $\mathrm{d} / / \mathrm{d} t$ as input and current originating at ground level for triggered-lightning flash S0123. Model-predicted results are compared with measured waveforms. Note that the timescales are not the same as in Figure 3.

shown in Figure 5) was measured approximately $160 \mathrm{~m}$ from a natural negative first return stroke. The stroke location was determined with a time-difference-of-arrival method using $\mathrm{d} E / \mathrm{d} t$ waveforms recorded at three stations. Similar close first-stroke waveforms for other natural flashes have been recorded with the MSE since 2002. The overall structure of the natural first-stroke waveform presented in Figure 4 is remarkably similar to that of the triggered-stroke waveforms presented in Figure 3, specifically the signature of the downward leader step (which is similar to that observed for the 30-m triggered-lightning $\mathrm{d} E / \mathrm{d} t$ waveform) and the slow front. The slow front of the natural-lightning first stroke has a duration of about $5 \mu$ s compared to about $2.2 \mu$ s for the triggered-lightning stroke. At least three pulses are observed to be superimposed on the natural-lightning slow front waveform, similar to those observed for the triggeredlightning stroke. In addition, the natural-lightning slow front of the natural-lightning $\mathrm{d} E / \mathrm{d} t$ waveform is preceded by two bursts of (primarily unipolar) pulses, each having a duration of about $2 \mu \mathrm{s}$, which do not have the same shape as the previous leader-step signatures. The $15-\mathrm{m} \mathrm{d} B / \mathrm{d} t$ triggered-lightning waveform of Figure 3 appears to have a similar burst of pulses (though the duration is on the order of $0.5 \mu \mathrm{s}$ ), but these pulses may actually be associ- ated with the final leader step (discussed in more detail in sections 3.1 and 5.4), based on the time coincidence with leader signatures of the corresponding $\mathrm{d} E / \mathrm{d} t$ measurements.

\section{Modeling}

[18] Figure 6 shows field derivatives calculated using the single-wave transmission line (TL) model [Uman and McLain, 1969] with a constant return stroke speed of $10^{8} \mathrm{~m} \mathrm{~s}^{-1}$, a straight and vertical channel, and the current originating at ground level (presence of the strike object and an upward leader is neglected). The model calculations of Figure 6 are compared with the corresponding measured data. Measured $\mathrm{d} I / \mathrm{d} t$ was used as input to the TL model, and the entire current waveform, including both the slow front and the fast transition, is assumed to propagate vertically up the channel from ground level without distortion or attenuation. This simple model reasonably reproduces both the slow front and the fast transition in the field derivatives, considering that no account is taken of actual channel geometry and that the presence of the strike object and an upward connecting leader is ignored. Note that the first microsecond or so of the measured field-derivative waveforms in Figure 6 is thought to be due to the superposition 


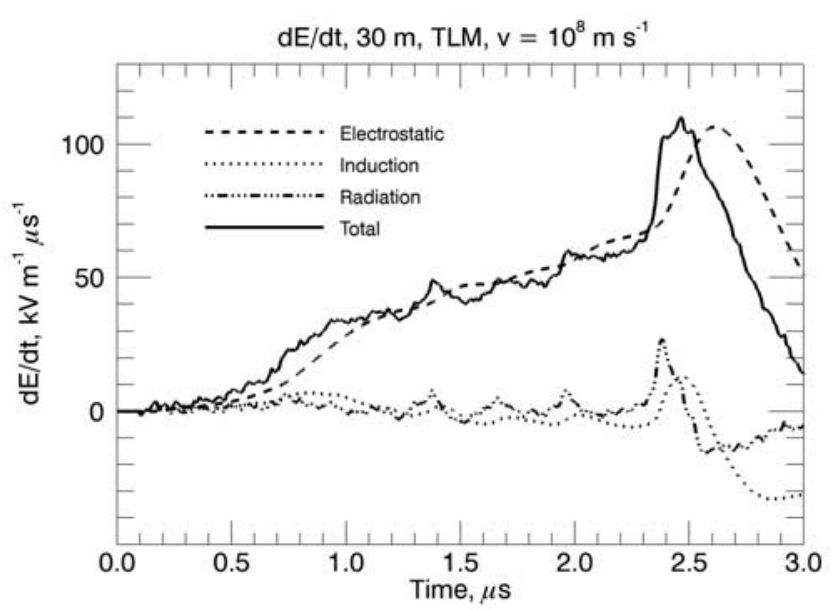

Figure 7. Electrostatic, induction, and radiation field components (defined by the formula of Uman et al. [1975]) for $\mathrm{d} E / \mathrm{d} t$ at $30 \mathrm{~m}$ calculated using the single-wave transmission line model (TLM) at a speed of $10^{8} \mathrm{~m} \mathrm{~s}^{-1}$ with $\mathrm{d} I / \mathrm{d} t$ as input and current originating at ground level. The total field (sum of the three components) is also shown and is the same as that in Figure 6 (the lower right panel). The timescale corresponds to those in Figure 6.

of the fields from the downward leader step and the beginning of the slow front as discussed in section 3. Since the downward leader-step signature is not observed in the $\mathrm{d} I / \mathrm{d} t$ waveform measured at ground, it is not reproduced by the model. The best match for the slow front is found with $\mathrm{d} B / \mathrm{d} t$ at $15 \mathrm{~m}$, a result which was fairly insensitive to the chosen return-stroke speed. In contrast, both model-predicted $\mathrm{d} E / \mathrm{d} t$ waveforms (primarily the electrostatic component) were found to be sensitive to the chosen return stroke speed, with speeds less than $10^{8} \mathrm{~m} \mathrm{~s}^{-1}$ producing the poorest results. The $\mathrm{d} E / \mathrm{d} t$ and $\mathrm{d} B / \mathrm{d} t$ slow fronts were found to be primarily composed of electrostatic and induction field components (the individual field components being defined by the formula of Uman et al. [1975]), respectively, with the pulses on the slow front in both cases being primarily radiation field. Figure 7 shows the calculated field components for $\mathrm{d} E / \mathrm{d} t$ at $30 \mathrm{~m}$. While the single-wave TL model reproduces the slow front remarkably well, the match for the pulse associated with the fast transition is not as good. Specifically, for the fast-transition pulse, the model-predicted field derivatives lack the double peak observed in the measured waveforms and are smaller in amplitude than the measured data.

[19] A two-wave version of the TL model, which is more physically reasonable than the single-wave version, was implemented in an attempt to more accurately reproduce the amplitude and fine structure of the measured fieldderivative peaks. Willett et al. [1988], who, for triggered lightning, compared electric fields measured at approximately $5 \mathrm{~km}$ with those predicted by the TL model, using measured channel-base current as input, observed the best match when they assumed two wave fronts traveling upward and downward away from the junction point of the upward and downward leaders, with the downward wave partially reflected at ground. In our two-wave model, a straight vertical channel is assumed (as before), with the upward and downward $\mathrm{d} I / \mathrm{d} t$ waves both being initiated from a junction point $6.5 \mathrm{~m}$ above ground (the height chosen based on the video analysis discussed in section 3 ) and with the amplitude of both waves being equal to $\mathrm{d} I / \mathrm{d} t$ measured at ground. Both waves propagate without attenuation or distortion. The assumption that the amplitude of the downward wave is equal to the current measured at ground requires the current reflection coefficient at ground to be 0 , i.e., the channel is terminated in its characteristic impedance. The upward and downward waves were assumed to propagate at constant speeds of $0.95 \times 10^{8}$ and $1.55 \times 10^{8} \mathrm{~m} \mathrm{~s}^{-1}$, respectively. At $1.55 \times 10^{8} \mathrm{~m} \mathrm{~s}^{-1}$, the time required for the downward wave to propagate $6.5 \mathrm{~m}$ is only about 42 ns (much shorter than the 2.2- $\mu$ s overall duration of the slow front), with this feature being further discussed below. This simple model ignores any impedance discontinuity between the lightning channel and the 4.5-mhigh strike object. The predictions of this model are presented in Figures 8 and 9. As with the single-wave model results shown in Figure 6, the slow front shown in Figure 8 is reproduced well by the two-wave model. In addition, the overall amplitude and fine structure of the fasttransition derivative pulse (shown on an expanded timescale in Figure 9) is better reproduced because of the increased radiation field of the two-wave model (relative to the singlewave model) that accentuates the fine structure of the measured $\mathrm{d} I / \mathrm{d} t$ waveform. Although the two-wave model reproduces the double-peak structure of the measured waveforms, the amplitudes of the second and subsequent peaks are smaller than the measured values. This is perhaps because these secondary peaks are the result of reflections at ground, the junction point, and/or the junction between the channel and the strike object. The assumption that the initial downward wave exhibits no reflection is unrealistic on its face [e.g., Rakov et al., 1998], yet our two-wave model reasonably reproduces both the slow front and the initial peak of the fasttransition derivative pulse in the measured waveforms. A possible explanation for this apparent contradiction is that multiple reflections between the ground and the junction point (and/or the top of the strike object) may, on a microsecond timescale during the slow front (which is much longer than the 42-ns propagation time of the downward wave at about half the speed of light), give the appearance of a single downward wave (below the junction point that is) absorbed at ground, consistent with the assumptions of our two-wave model. In this view, the $6.5-\mathrm{m}$ segment below the junction point is essentially a short circuit to ground during the slow front.

[20] The assumption of a junction height significantly greater than the $6.5 \mathrm{~m}$ we adopt $(6.5 \mathrm{~m}$ being consistent with the connection point of the upward and downward leaders inferred from video records to be a few meters above the 4.5-m strike object) in the two-wave model yields relatively poor model results. For example, for $\mathrm{d} E / \mathrm{d} t$ at $30 \mathrm{~m}$, the twowave model with a junction height of $25 \mathrm{~m}$ yields a fasttransition pulse with roughly half the amplitude and a significantly different wave shape from the pulse obtained using the 6.5-m junction height, with all other model parameters remaining the same.

[21] Figure 10 shows the separate contributions of the upward and downward waves of the two-wave model to the calculated field derivative at $30 \mathrm{~m}$. The contribution of 

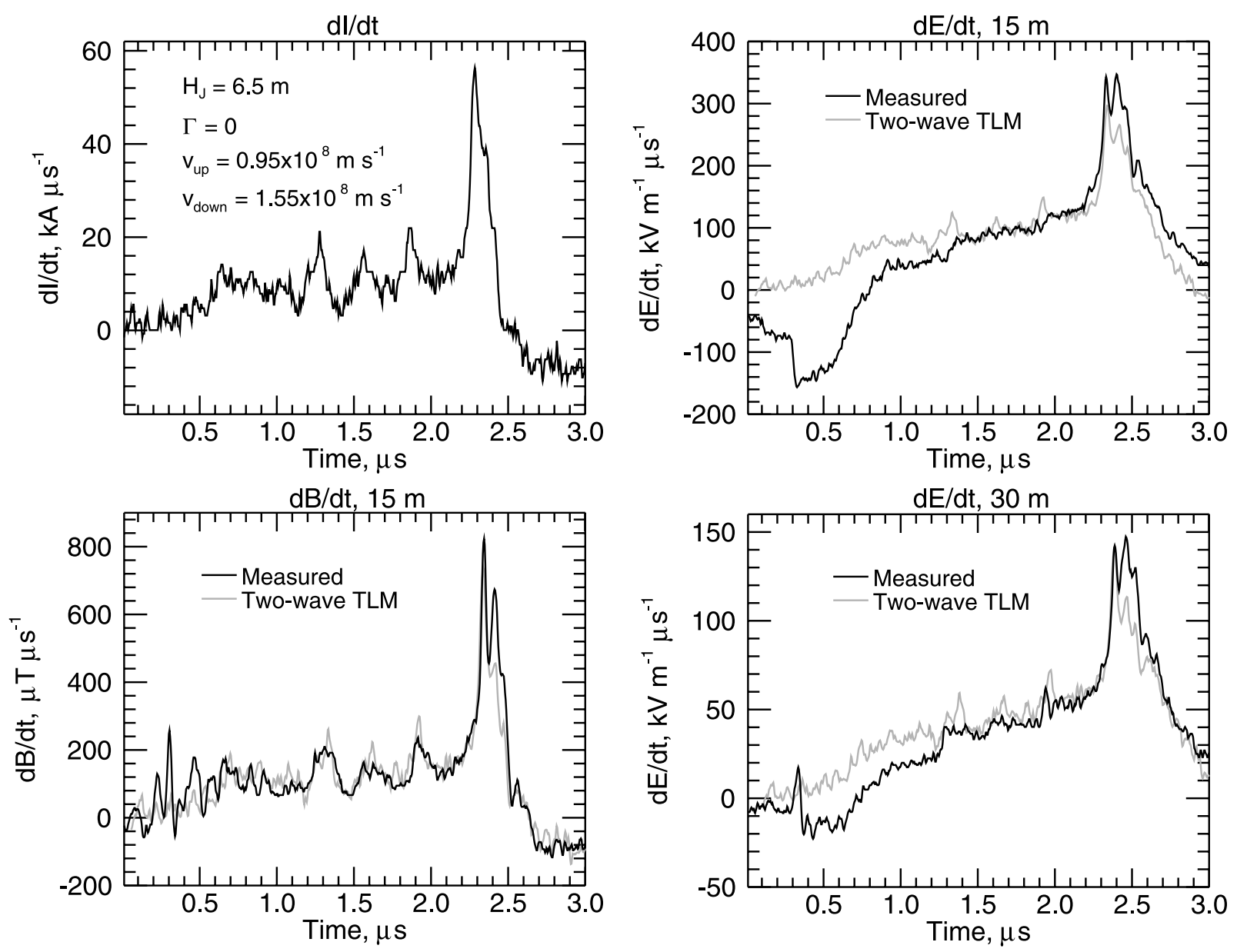

Figure 8. Field derivatives calculated using the two-wave transmission line model (TLM) with $\mathrm{d} I / \mathrm{d} t$ as input and current originating at a height of $6.5 \mathrm{~m}$. Model parameters are given in the upper left panel, and the model-predicted results are compared with measured waveforms. $H_{\mathrm{J}}$ is the height of the junction point (origin of the upward and downward waves), $\Gamma$ is the reflection coefficient at ground, and $v_{\text {up }}$ and $v_{\text {down }}$ are the speeds of the upward and downward waves, respectively. The time values on the horizontal axes correspond to those in Figure 6.

the downward wave (speed of $1.55 \times 10^{8} \mathrm{~m} \mathrm{~s}^{-1}$ ) dominates that of the upward wave (speed of $0.95 \times 10^{8} \mathrm{~m} \mathrm{~s}^{-1}$ ). Interestingly, if both the upward and downward waves are assumed to have a speed of about $10^{8} \mathrm{~m} \mathrm{~s}^{-1}$ (results not shown here), the contribution of the downward wave still dominates that of the upward wave. This observation indicates that the current must be relatively close to the ground (as it is for the downward wave) in order for its field to be dominant at the measurement point on ground at a horizontal distance of $30 \mathrm{~m}$.

[22] While the two-wave model presented here provides the simplest best-case fit to all of our data, despite the arguably unrealistic assumptions, other more complex models (that include reflections at ground and/or at the top of the strike object), such as that proposed by Miyazaki and Ishii [2006], may also yield equally good or better results. Unfortunately, the differences between the integrated $\mathrm{d} I / \mathrm{d} t$ and the directly measured fast-transition currents (uncertainty in the fine details of the waveforms as discussed in section 3) render more detailed fast-transition modeling of limited value, although the modeling results for the slow front would appear not to be changed by more sophisticated modeling. Both the single-wave (Figure 6) and the two-wave (Figure 8) TL models reasonably reproduce the measured field-derivative slow fronts. This is because it is primarily the radiation field that is changed by going from the single-wave model to the two-wave model, while the slow fronts (excluding the superimposed pulses) are relatively insensitive to the change due to being composed mainly of electrostatic and induction field components.

[23] The distant electric and magnetic (radiation) fields, calculated using the single-wave TL model, will have the exact same wave shape as the corresponding channel-base current, assuming propagation over a perfectly conducting ground. Specifically, the single-wave TL model implies that for distances $D \gg H$ and times $t<H / v$, where $H$ is the height of the channel and $v$ is the upward propagation speed, the magnitude of the electric field $E(t)$ is related to the channel-base current $I(t)$ by

$$
E(t)=\frac{\mu_{o} v}{2 \pi D} I(t-D / c) .
$$



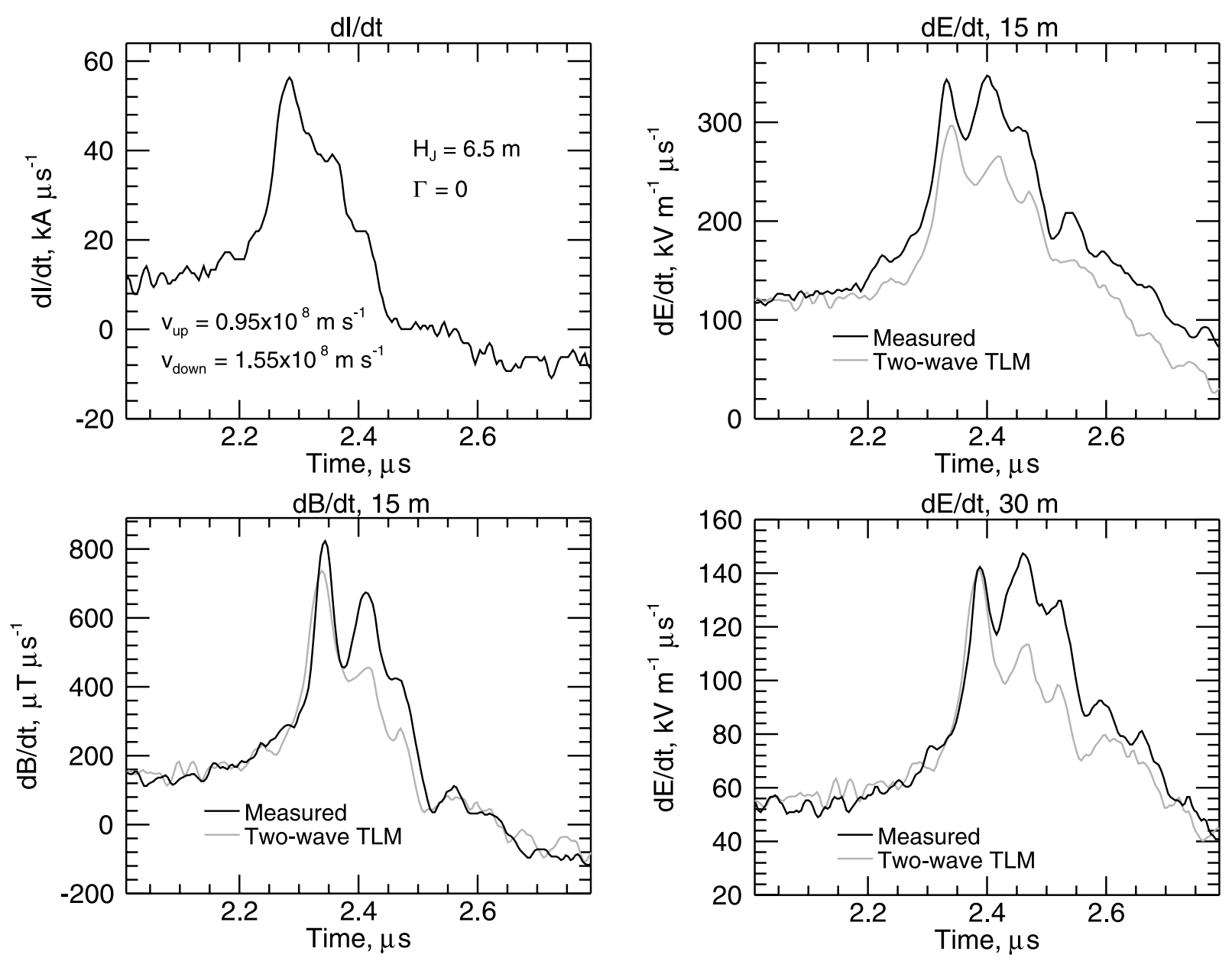

Figure 9. Field derivatives calculated using the two-wave transmission line model (TLM) with $\mathrm{d} I / \mathrm{d} t$ as input and current originating at a height of $6.5 \mathrm{~m}$. The model results are the same as presented in Figure 8 , but are plotted on an expanded timescale around the fast transition. Model parameters are given in the upper left panel, and the model-predicted results are compared with measured waveforms. $H_{\mathrm{J}}$ is the height of the junction point (origin of the upward and downward waves), $\Gamma$ is the reflection coefficient at ground, and $v_{\text {up }}$ and $v_{\text {down }}$ are the speeds of the upward and downward waves, respectively. The time values on the horizontal axes correspond to those in Figures 6 and 8.

The corresponding distant magnetic field, $B(t)$, is equal to the electric field scaled by a factor of $-1 / c$. Figure 11 shows the electric field at $100 \mathrm{~km}$ calculated using the single-wave and two-wave TL models, assuming propagation over a perfectly conducting ground. The field predicted by the single-wave model has the same wave shape as the current, as expected, with the field predicted by the two-wave model looking similar. The primary difference between the singlewave and two-wave results is that, for the latter, the fast transition has a shorter risetime and the three slow-front pulses are more accentuated. This is consistent with the observation that the two-wave model primarily enhances the calculated radiation field, relative to the single-wave model. The model-predicted peak fields at $100 \mathrm{~km}$, about 5.4 and $5.6 \mathrm{~V} \mathrm{~m}^{-1}$ for the single-wave and two-wave models, respectively, are consistent with previously reported mean peak fields of 5-7 $\mathrm{V} \mathrm{m}^{-1}$ (normalized to a distance of $100 \mathrm{~km}$ ) for distant natural negative lightning first strokes [e.g., Lin et al., 1979; Cooray and Lundquist, 1982; Rakov and Uman, 1990; Rakov et al., 1994]. This is not surprising since the peak current of our triggered-lightning stroke (27$29 \mathrm{kA}$ ) is very close to the median peak current of $30 \mathrm{kA}$ reported by Berger et al. [1975] for natural negative lightning first strokes.

\section{Discussion}

\subsection{Interpretation of Modeling Results}

[24] In view of our data and various observations to be discussed in this section, we propose the following idealized model of the attachment process. As the downward negative leader approaches ground, an upward positive leader is initiated from ground or a ground-based object. This upward leader apparently exhibits stepping as observed by Wang et al. [2001]. The upward and downward leaders propagate with roughly the same average speed on the order of $10^{5} \mathrm{~m} \mathrm{~s}^{-1}$. This view is consistent with the mechanisms proposed by Wang et al. [2001] for natural-lightning first strokes and Wang et al. [1999a] for triggered-lightning strokes. When the two leaders are in close proximity, with 


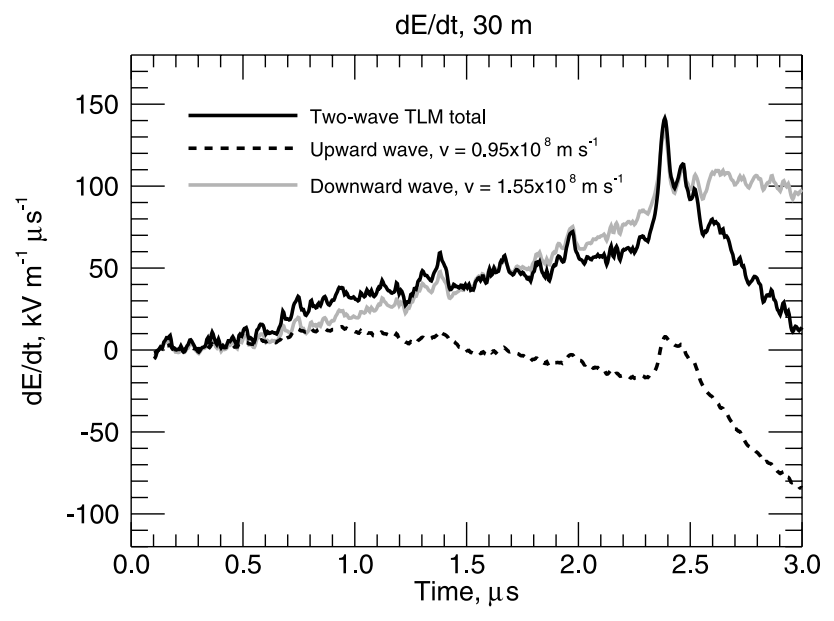

Figure 10. Contributions from upward (dotted curve) and downward (solid gray curve) waves to the model-predicted $\mathrm{d} E / \mathrm{d} t$ waveform at $30 \mathrm{~m}$ calculated using the two-wave transmission line model (TLM) with $\mathrm{d} I / \mathrm{d} t$ as input and current originating at a height of $6.5 \mathrm{~m}$. The total field (sum of the two components) is also shown (solid black curve) and is the same as that in Figures 8 and 9 (the lower right panel in each figure). The timescale corresponds to those in Figures 6 and 8.

the descending leader tip being at a height of a few to some tens of meters above ground, the charge at their tips causes them to accelerate toward each other over a distance of some meters in a time of some microseconds. This produces a corresponding increase in current in both leader channels near the junction point, in effect launching the slow-front current waves which propagate in both directions, upward and downward from the region of the junction, at speeds on the order of $10^{8} \mathrm{~m} \mathrm{~s}^{-1}$. Thus the process of connection between upward and downward leaders is viewed here as responsible for the slow front observed in both measured currents and fields. The final connection between the two leaders creates the fast-transition current pulse, which also propagates away from the junction point in both directions. Note that in this view, consistent with those of Gorin [1985] and Rakov and Dulzon [1991], the slow front and fast transition are probably not two distinct processes but rather are stages of one continuous process.

[25] The model just outlined is also plausible for subsequent strokes initiated by dart leaders, but since the source of the front currents must be the descending dart leader charge and the corresponding upward connecting leader charge, one would expect subsequent-stroke slow-front current waves to be smaller in amplitude and of shorter time duration than those for first strokes due to the dart leader's having about a factor of 5 lower charge per unit length and an order to 2 orders of magnitude higher speed [Rakov and Uman, 2003, p. 7]. Indeed, if one considers typical overall peak currents for negative natural-lightning first strokes initiated by stepped leaders and negative subsequent strokes initiated by dart leaders (about 30 and $12 \mathrm{kA}$, respectively, according to Rakov and Uman [2003]) and the ratios of the corresponding average peak front amplitude to total peak for distant fields observed by Weidman and Krider [1978] (about 0.4 and 0.2, respectively), the ratio of the first stroke to subsequent stroke peak front currents can be inferred to be about 5, with the fast-transition currents being similar in amplitude. Hence, in this view, the primary difference between first and subsequent return strokes is the attachment process, the acceleration and connection of the two leaders, with the ratio of the peak slowfront values for first and subsequent strokes being the ratio of the respective leader line charge densities and the fasttransition pulse being similar in both cases.

[26] As noted previously, one prediction of the single-wave TL model is that the calculated distant electric and magnetic fields have the same wave shape as the current, assuming propagation over a perfectly conducting ground, with the electric field and current being related by equation (1). An important implication of this result is that the TL model may well be suitable for estimating first-stroke currents (at least up until the peak, according to Willett et al. [1988] and Schoene et al. [2003]) from distant electric and magnetic radiation fields, although this would require assumptions regarding return-stroke speed and upward leader length, along with knowledge of the distance from the lightning channel. The triggered-stroke discussed here was detected by the U.S. National Lightning Detection Network (NLDN), which locates strokes in the contiguous United States with a median error of about 500-600 m [Cummins et al., 1998; Jerauld et al., 2005]. The peak current for each detected stroke is estimated from the peak magnetic fields measured by the individual sensors (originally using the TL model and now using an empirical relationship obtained using the triggered-lightning data of Idone et al. [1993] and a model to account for propagation effects, the result being equivalent to the TL model to first approximation). For the triggered

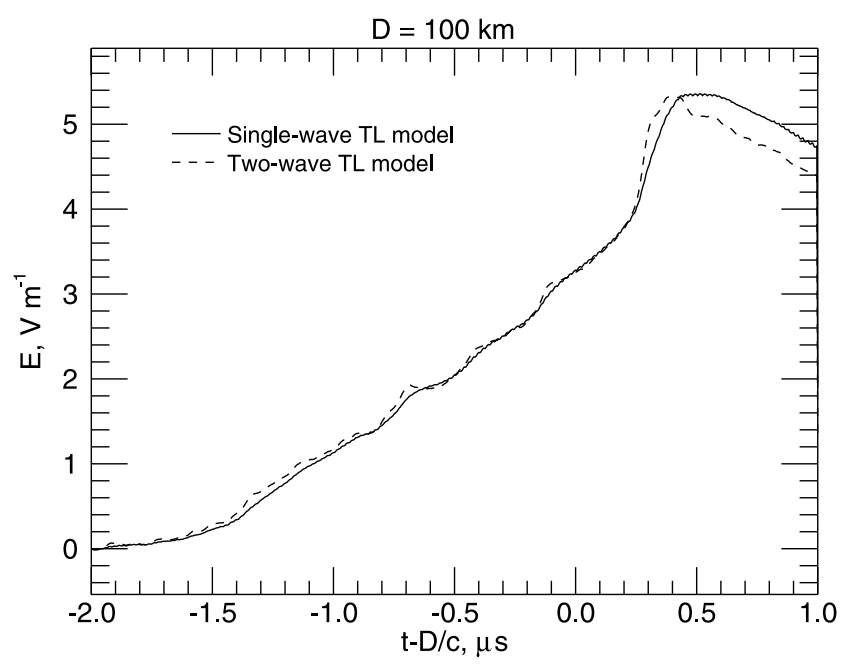

Figure 11. Electric fields at $100 \mathrm{~km}$ calculated using the single- and two-wave transmission line (TL) models, assuming propagation over a perfectly conducting ground. Integrated $\mathrm{d} I / \mathrm{d} t$ was used as input to both models, and model parameters are the same as those used in the calculations shown in Figures 6 (for single-wave model) and 8 (for two-wave model). The timescale has been normalized to account for the propagation over $100 \mathrm{~km}$ and corresponds to the time values in Figure 2. The electric field waveform for the single-wave model has the same shape as that of current (see Figure 2), as follows from equation (1). 
stroke discussed here, the NLDN reported a peak current of $20.4 \mathrm{kA}$. Interestingly, if one considers the $-18 \%$ median current estimation error reported for subsequent (triggeredlightning) strokes for 2001-2003 by Jerauld et al. [2005] (the triggered-lightning stroke discussed here was included in that study), the NLDN peak current estimate is consistent with the measured peak 27-29 kA. Note that in July 2004, a new propagation model was introduced in order to alleviate the discrepancies in NLDN-estimated peak current reported by Jerauld et al. [2005] [Cummins et al., 2006]. On the other hand, Willett et al. [1989a], who examined measured waveforms of channel-base current and corresponding electric field at a distance of about $5 \mathrm{~km}$ for 28 triggered-lightning strokes, stated that the electric field waveforms for two of these strokes exhibited pronounced slow fronts which did not appear in the corresponding current waveforms, although neither these waveforms nor their detailed descriptions were presented. They concluded that in these two cases, "the fronts cannot be explained by the TLM." Perhaps these observations are to be associated with an unusual leader rather than with the slow front process considered here.

[27] Weidman and Krider [1978] attempted to reproduce the measured field slow fronts by modeling a single upward connecting discharge with both velocity and current rising exponentially to peak (both having the same time constant), justified by observations of exponential increases in upward "streamer" velocity in long laboratory sparks [Wagner, 1960]. In their model, the initial upward velocity in all cases was set to $10^{5} \mathrm{~m} \mathrm{~s}^{-1}$. In their Figure $13 \mathrm{a}$, electric fields at $100 \mathrm{~km}$ were calculated by constraining the final velocity to be $10^{7} \mathrm{~m} \mathrm{~s}^{-1}$ and varying the maximum current from 1 to $40 \mathrm{kA}$, with the final discharge length being $21.4 \mathrm{~m}$ in all cases. In their Figure 13b, the final current was held at $10 \mathrm{kA}$, and the maximum upward velocity ranged from $10^{6}$ to $10^{8} \mathrm{~m} \mathrm{~s}^{-1}$. The final upward discharge lengths ranged between 3.9 and $144.6 \mathrm{~m}$. While the shapes and durations of the calculated fields were similar to their measured data, the calculated field amplitudes tended to be much smaller than the measured peak-field mean of $5-7 \mathrm{~V} \mathrm{~m}^{-1}$ at $100 \mathrm{~km}$, using reasonable upward channel lengths and currents; "reasonable" being defined as a final length of less than $30 \mathrm{~m}$ and a final current of about $10 \mathrm{kA}$. Weidman and Krider [1978] thus concluded that a single upward propagating discharge apparently cannot radiate the observed slow-front field (half the total field peak) with reasonable channel lengths and currents, and they offered two alternative hypotheses, one of which was that several upward discharges radiate simultaneously. The other was that a large surge of current occurs in the leader channel during the growth of the upward connecting discharge. In this case, the predicted radiation field will be smaller than observed unless the leader surge rises to a value of $10 \mathrm{kA}$ and propagates along a channel length approaching $1 \mathrm{~km}$, a view supporting our two-wave modeling.

[28] Attempts to model slow fronts have also been made by Thottappillil and Uman [1993] and Cooray et al. [2004]. Thottappillil and Uman [1993] considered two possible sources for the slow front in current waveforms: an upward connecting leader (or leaders) and the return-stroke process itself. They showed (see their Figure 10) that a better agreement between the initial peaks of the calculated and measured radiation fields of a triggered-lightning stroke for the case of a measured current waveform containing a slow front (having a duration of about $0.4 \mu$ s and an amplitude less than $20 \%$ of the peak) could be obtained if the returnstroke speed was assumed to increase exponentially from a small value to the optically measured value. Cooray et al. [2004] associated the slow front in the channel-base current waveform with an accelerating upward connecting leader and mathematically incorporated this feature into their travelling current source-type model as a modification of the speed profile of the discharge. Their speed profile is characterized by an initial increase with increasing height, up to the junction point, and a decrease above this point, consistent with recent optical measurements of return-stroke speed by Olsen et al. [2004].

\subsection{Other Measurements of Slow Fronts in Natural and Altitude-Triggered Lightning}

[29] Wang et al. [2001] present correlated electric field measurements and high-speed optical images for two natural-lightning first return strokes that occurred within a few kilometers of the observation site. The $E$-field measurement is stated to have a time constant of $100 \mathrm{~ms}$, a highfrequency limit of $10 \mathrm{MHz}$, and a sampling interval of 80 ns. The latter was recorded with the Automatic Lightning Progressing Feature Observation System (ALPS) [Yokoyama et al., 1990], the same system used in the studies of Wang et al. $[1999 \mathrm{a}, 1999 \mathrm{~b}]$, consisting of a $16 \times 16$ array of photodiodes whose outputs were sampled at $10 \mathrm{MHz}$. Both instruments were located on the roof of a small building. The ALPS system, whose output triggered the $E$-field system, was triggered from the light of the return-stroke channel, thus the two measurements were synchronized on a submicrosecond scale. For the first event discussed, an upward leader was observed by ALPS to advance a distance of about $88 \mathrm{~m}$ over $53 \mu \mathrm{s}$, thus having an average speed of $1.7 \times 10^{6} \mathrm{~m} \mathrm{~s}^{-1}$, initiated when the downward stepped leader (estimated to have an average speed of $4 \times 10^{6} \mathrm{~m} \mathrm{~s}^{-1}$ ) was at a height of about $300 \mathrm{~m}$. Furthermore, the observed upward leader ends before the beginning of the slow front in the $E$-field record (the latter having a duration of a few microseconds), and thus it is unlikely that the slow front in this event is due to the upward connecting discharge, which is consistent with our idealized model of the attachment process and our two-wave TL modeling, in which the junction of the upward and downward leaders, not the upward leader itself, is the source of the slow front.

[30] Wang et al. [2001] also observed a unipolar electric field pulse, having a risetime of $0.5 \mu$ s and a width of less than $2 \mu \mathrm{s}$ (before being overwhelmed by the slow front), occurring immediately before the slow front. Wang et al. [2001] were not able to explain the pulse, as apparently the only corresponding optical signal was a single pulse observed in the lowest channel section (about $35 \mathrm{~m}$ above ground), which was overwhelmed by a fast transition after about $1.5 \mu \mathrm{s}$. This pulse may be related to the burst of $\mathrm{d} E / \mathrm{d} t$ pulses preceding the slow front observed for the close naturallightning first stroke discussed here (see section 3.2) and the observations of Murray et al. [2005] for distant natural lightning (discussed in detail in section 5.3).

[31] Slow fronts are also observed in published currents and fields of first strokes in altitude-triggered lightning, which are similar to natural first strokes in that they are also initiated by downward stepped leaders [Lalande et al., 
1998; Rakov et al., 1998; Chen et al., 2003]. The triggering wire in altitude-triggered lightning is not attached to ground, allowing a stepped leader to descend through virgin air from the bottom of the conducting triggering wire, typically located some hundreds of meters above ground. The ground attachment point is unpredictable, hence sometimes a conducting "intercepting" wire (typically $50 \mathrm{~m}$ long) connected to the rocket launcher is employed to facilitate attachment, so that lightning current can be directly measured. Altitudetriggered lightning allows the study of stepped leaders, usually not possible with classical-triggered lightning, although the former process is considerably more complicated than the latter due to the development of a bidirectional leader from the two ends of the floating triggering wire and the subsequent destruction of that wire due to current flow [Lalande et al., 1998; Rakov et al., 1998; Chen et al., 2003]. Lalande et al. [1998] discuss a negative altitude-triggered event (designated 9516) in which the first-stroke current (measured at the base of the intercepting wire with a shunt) exhibits a pulse with a concave front having a peak of about $5 \mathrm{kA}$ and a duration of 5-6 $\mu \mathrm{s}$ before an abrupt decrease in current, presumed to be due to the destruction of the $50 \mathrm{~m}$ grounded intercepting wire. After a no-current (or very small current) interval of about $5 \mu \mathrm{s}$, the current resumes, rising to a peak of about $12 \mathrm{kA}$ (see their Figure 11). The process of cutoff and reestablishment of current may well be similar to that observed in classical-triggered lightning by Rakov et al. [2003] and Olsen et al. [2006]. The slow front observed in the work of Lalande et al. [1998] is not described as such, but it does exhibit the typical concave shape, duration, and amplitude to total peak current ratio (the peak current occurring after the no-current interval) observed for both measured first-stroke currents and distant fields as described above. Furthermore, the slow-front electric and magnetic fields measured at $50 \mathrm{~m}$ (see their Figure 11) are similar to those measured for close naturallightning first strokes, such as the event shown in Figures 4 and 5. The origin of the concave slow front (note that Lalande et al. [1998] never use the term "slow front") in their waveforms is not discussed. The upward connecting leader, initiated from the top of the $50-\mathrm{m}$ intercepting wire, is estimated from current records (see their Figure 8) to have a duration of about $350 \mu$ s before the beginning of the slow front with the upward leader current consisting primarily of pulses on the order of a few tens to $100 \mathrm{~A}$, separated by $20 \mu \mathrm{s}$ or so, superimposed on a monotonically increasing current of similar amplitude. Thus this upward leader current cannot be the source of the slow front. On the basis of two-dimensional optical records, the length of the upward connecting leader above the top of the $50-\mathrm{m}$ interception wire is estimated to be about $20 \mathrm{~m}$. Using the estimated upward leader height $(20 \mathrm{~m})$ and duration $(350 \mu \mathrm{s})$, the average upward connecting leader speed is estimated to be $0.57 \times 10^{5} \mathrm{~m} \mathrm{~s}^{-1}$. Since the length of the upward connecting leader is estimated from a two-dimensional photograph, the three-dimensional speed is likely higher but still on the order of $10^{5} \mathrm{~m} \mathrm{~s}^{-1}$.

[32] Chen et al. [2003] describe simultaneous observations of optical and electric field signals from altitudetriggered lightning in China. Optical signals were recorded at a distance of $1300 \mathrm{~m}$ by the ALPS system described above. Electric fields were measured by flat-plate antennas at distances of 60 and $1300 \mathrm{~m}$ from the launcher. Chen et al.
[2003] observe a slow front in the electric field record having a duration of roughly $3 \mu$ s (see their Figure 10). This front is immediately preceded by an isolated unipolar pulse having a width of roughly $0.7 \mu \mathrm{s}$ and a risetime of $0.2 \mu \mathrm{s}$, not dissimilar from that described by Wang et al. [2001] for natural first strokes. A corresponding pulse is observed in (and only in) the lowest optical waveform (viewing channel heights between 0 and $55 \mathrm{~m}$ above ground) recorded by the ALPS system. Although the observations of Chen et al. [2003] and Wang et al. [2001] are similar, the interpretations offered by the respective authors differ. Chen et al. [2003] attribute the isolated optical pulse (and presumably the corresponding electric field pulse) to the upward connecting leader from ground. The connection between the downward negative leader and upward connecting leader is assumed to begin about $2 \mu \mathrm{s}$ after the isolated pulse, during the slowfront portion of the electric field waveform, when the light signals from the lowest two segments $(0-55$ and $55-111 \mathrm{~m})$ begin to increase continuously. In contrast, as discussed above, Wang et al. [2001] report the upward leader occurring prior to the isolated pulse and slow front, and they are unable to identify the source of the isolated pulse, as it apparently was not found to be related to the upward leader. While the data of Wang et al. [2001] and Chen et al. [2003] appear to be similar, the interpretation of the data provided by Wang et al. [2001] supports our idealized two-wave model, while that of Chen et al. [2003] does not.

\subsection{Slow-Front Pulses}

[33] Murray et al. [2005] examined $131 \mathrm{distant} \mathrm{d} E / \mathrm{d} t$ and $E$ waveforms from natural negative first strokes that propagated over ocean water to the measurement site, and they performed an analysis on the fine structure within the 5- $\mu \mathrm{s}$ interval that corresponds to the onset of the first-stroke waveforms, that is, -4 to $+1 \mu \mathrm{s}$ of the "dominant" $\mathrm{d} E / \mathrm{d} t$ peak (where the time of the dominant $\mathrm{d} E / \mathrm{d} t$ peak is set at 0 ), an interval that typically includes the slow front. The events were separated into three categories: Type A events having only the single dominant $\mathrm{d} E / \mathrm{d} t$ peak within the 5- $\mu \mathrm{s}$ interval, Type B events having one or more $\mathrm{d} E / \mathrm{d} t$ peaks (that meet their selection criteria) within $\pm 1 \mu \mathrm{s}$ of the dominant peak, and Type $\mathrm{C}$ events having one or more $\mathrm{d} E / \mathrm{d} t$ pulses within -4 to $-1 \mu \mathrm{s}$ of the dominant peak but no pulses within $\pm 1 \mu$ s of the dominant peak. These Type $\mathrm{C}$ events, producing a total of $85 \mathrm{~d} E / \mathrm{d} t$ pulses in the interval between -4 and $-1 \mu \mathrm{s}$, account for about $28 \%$ (37 out of 131) of the total strokes analyzed. Thus the average number of $\mathrm{d} E / \mathrm{d} t$ pulses, not including the dominant peak, in Type C strokes is 2.3. Murray et al. [2005] note that some of the Type B events also had pulses between -4 and $-1 \mu \mathrm{s}$, thus the percentage of strokes having $\mathrm{d} E / \mathrm{d} t$ pulses in the interval of -4 to $-1 \mu \mathrm{s}$ is higher than the $28 \%$ given for Type $\mathrm{C}$ strokes only. In addition, since Type B events also include pulses in the interval of -1 to $0 \mu \mathrm{s}$, the average number of $\mathrm{d} E / \mathrm{d} t$ pulses occurring during the slow front (not including the dominant $\mathrm{d} E / \mathrm{d} t$ peak) is likely higher. Regardless, the average number of $\mathrm{d} E / \mathrm{d} t$ pulses occurring during the slow front reported by Murray et al. [2005] is consistent with the number observed in our triggered stroke (3, see Figure 3) and our natural first stroke (at least 3, see Figure 4). Murray et al. [2005] do not speculate as to the nature of these pulses but contend that the data suggest that the lightning 
attachment process is considerably more complicated than generally assumed. Interestingly, three distinct channels are observed in the video records (see Figure 1), and three distinct pulses are observed on the $\mathrm{d} E / \mathrm{d} t$ slow fronts of Figure 3. Each pulse may perhaps correspond to the formation of a separate channel section although this is certainly speculation.

[34] As discussed in section 4, our modeling suggests that the triggered-lightning slow-front derivative pulses are primarily radiation field. Interestingly, for the $\mathrm{d} E / \mathrm{d} t$ waveform at $30 \mathrm{~m}$ calculated using the single-wave TL model shown in Figure 7 , the radiation field of the slow-front pulses looks similar to the radiation field of the fast-transition pulse although the latter is larger in amplitude. Furthermore, the distant radiation $\mathrm{d} E / \mathrm{d} t$ pulses observed in Type $\mathrm{B}$ and $\mathrm{C}$ events by Murray et al. [2005] appear similar to the dominant $\mathrm{d} E / \mathrm{d} t$ pulse. This similarity suggests that the radiation fields of the slow-front pulses and of the fast-transition pulse are produced by a similar physical mechanism.

[35] As mentioned in section 3.2, the slow front in the firststroke $\mathrm{d} E / \mathrm{d} t$ waveform shown in Figure 4 is preceded by two bursts of (primarily unipolar) pulses, each having a duration of about $2 \mu \mathrm{s}$, which do not have the same shape as the previous leader step signatures. The $15-\mathrm{m} \mathrm{d} B / \mathrm{d} t$ waveform of Figure 3 appears to have a similar burst of pulses (though the duration is on the order of $0.5 \mu \mathrm{s}$ ), but these pulses may actually be associated with the final leader step (discussed in more detail in section 5.4), based on the time coincidence with leader signatures of the corresponding $\mathrm{d} E / \mathrm{d} t$ measurements. Murray et al. [2005] apparently also observed similar $\mathrm{d} E / \mathrm{d} t$ pulses during the beginning of the slow front, as can be seen in their Figures 1, 5, 6, 8, 11, and 12, some of which are labeled as "leader bursts."

\subsection{Stepped Leader}

[36] As discussed in section 3, for the triggered-lightning stroke, the signature of the downward leader step differs significantly between the $15-$ and $30-\mathrm{m} \mathrm{d} E / \mathrm{d} t$ waveforms, with the $30-\mathrm{m}$ step signature being similar to that of the natural-lightning first-stroke leader shown in Figure 4. Specifically, negative transitions observed in the $15-\mathrm{m}$ leader step $\mathrm{d} E / \mathrm{d} t$ waveform (the largest occurring at time $-1.7 \mu \mathrm{s}$ in Figure 3 ) correspond to positive pulses in the 30-m waveform. The dominant feature in the different measured leader step derivative waveforms at the two distances (occurring at time $-1.7 \mu$ s in Figure 3 ) is generally consistent according to our modeling, with a source current pulse, having a peak of a few kiloamperes and a pulse width of about $0.1 \mu \mathrm{s}$, propagating upward from a height of about $10 \mathrm{~m}$ above ground (about $5 \mathrm{~m}$ above the top of the strike object).

[37] This view of the leader step is supported by optical observations of leader steps, such as those of Wang et al. [1999b] and Chen et al. [1999] who (both groups) reported luminosity waves associated with individual steps that propagated in the direction opposite to that of the advancement of the downward leader. A peak step current of a few kiloamperes is also consistent with the estimates of Krehbiel [1981] and Thomson [1985], based on electric field measurements, and of Rakov et al. [1998] for a dart-stepped leader based on magnetic field measurements. Finally, a downward leader step source height of about $10 \mathrm{~m}$ above ground is consistent with the estimate of the junction point being only a few meters above the top of the 4.5-m strike object. The construction of models of the leader step using these and other similar data is the subject of a future paper.

\section{Summary}

[38] We have presented measured current derivative $(\mathrm{d} I / \mathrm{d} t)$ and electric and magnetic field derivatives $(\mathrm{d} E / \mathrm{d} t$ and $\mathrm{d} B / \mathrm{d} t$, respectively) for the third stroke in a five-stroke triggered-lightning flash initiated using the classical rocketand-wire technique, and we compared those data with similar data from a natural negative lightning first return stroke.

[39] The triggered-lightning stroke was initiated by a dartstepped leader, as evidenced by field-derivative records, and optical records indicate that the junction point between the upward and downward leaders likely occurred a few meters above the strike object. The numerically integrated $\mathrm{d} I / \mathrm{d} t$ (i.e., current) waveform is comprised of a "slow front" rising to about $20 \mathrm{kA}$ in $2.2 \mu \mathrm{s}$, followed by a "fast transition" rising to a peak of about $27 \mathrm{kA}$ in about $0.2 \mu \mathrm{s}$. This slow-front/fast-transition sequence is similar to those observed for negative first-stroke currents measured on tall towers [e.g., Berger et al., 1975], distant radiation fields [e.g., Weidman and Krider, 1978], and measured currents and fields in altitude-triggered lightning [e.g., Lalande et al., 1998]. $\mathrm{d} E / \mathrm{d} t$ and $\mathrm{d} B / \mathrm{d} t$ waveforms measured at 15 and $30 \mathrm{~m}$ are similar to those observed for close (within a few hundred meters) negative first strokes recorded by the multiple-station field-measuring network at the ICLRT. For the triggered-lightning stroke, pulses are observed during the slow fronts in both $\mathrm{d} I / \mathrm{d} t$ and field-derivative waveforms, not dissimilar from those observed by us for close natural lightning, and possibly are related to the pulses observed by Murray et al. [2005] to occur during the slow fronts of distant (radiation) $\mathrm{d} E / \mathrm{d} t$ waveforms.

[40] The similarity between the triggered-lightning stroke fields and the fields of close natural-lightning first strokes and the availability of the triggered-lightning current, in conjunction with modeling, suggest a unified picture of the natural first-stroke attachment process. The single-wave transmission line (TL) model [Uman and McLain, 1969], which assumes a current wave propagating up from ground at constant speed without attenuation or distortion, using measured $\mathrm{d} I / \mathrm{d} t$ as input and an assumed return-stroke speed of $10^{8} \mathrm{~m} \mathrm{~s}^{-1}$, is able to reasonably reproduce the slow fronts in the field-derivative waveforms measured at 15 and $30 \mathrm{~m}$. The overall peak and the fine structure of the fast transition are not reproduced as well by the single-wave TL model. A two-wave version of the TL model, consisting of both upward and downward travelling waves initiated from the junction point (located several meters above the 4.5-m strike object), provides a better match for the fast transition while retaining a good fit for the slow front. These modeling results, combined with the inferences from optical records for natural and triggered lightning, indicate that the source of the slow fronts observed in distant natural-lightning firststroke radiation fields (assuming the same source for slow fronts in both close and distant fields) is unlikely to be the upward connecting leader, as is often thought, but rather is a microsecond-scale current wave, having a peak of up to some 
tens of kiloamperes, propagating in opposite directions from the junction point at a speed on the order of $10^{8} \mathrm{~m} \mathrm{~s}^{-1}$, a process which is related to the connection of the upward and downward leaders. This hypothesis is consistent with the limited measurements of upward (both connecting and unconnected) positive leaders [e.g., McEachron, 1939; Berger and Vogelsanger, 1966, 1969; Yokoyama et al., 1990; Lalande et al., 1998], which indicate average speeds and currents on the order of $10^{5} \mathrm{~m} \mathrm{~s}^{-1}$ and some hundreds of amperes, respectively, these values being far lower than those required to account for the slow fronts observed in measured natural-lightning first-stroke currents and distant radiation fields.

[41] One important feature of the TL model is that the model-predicted distant radiation fields from naturallightning first strokes, including both the slow front and the fast transition, will have a wave shape similar to that of the current measured at ground (see Figure 11), at least until the peak, implying that some version of the TL model can be used to estimate first-stroke peak currents from measured distant electric and magnetic fields, when assumptions are made regarding the return-stroke speed and the length of the upward connecting leader, and distance from the lightning channel is known. Indeed, the NLDN-reported peak current of $20.4 \mathrm{kA}$ for the triggered-lightning stroke discussed here (which was estimated using a method similar to the TL model to a first approximation) is consistent with the measured peak current of 27-29 kA when one considers the NLDN median peak-current estimation error of $-18 \%$ reported by Jerauld et al. [2005] for 2001-2003. It is worth noting, however, that as of today, there are no simultaneous measurements of first-stroke current and distant field in natural lightning, the data needed in order to determine if both exhibit associated slow fronts.

[42] Acknowledgments. This work was supported in part by NSF grants ATM-0003994 and ATM-0346164, U.S. DOT (FAA) grant 99-G-043, the Florida Power and Light Corporation, the Florida Gas Transmission Group, and by the Florida Space Grant Consortium. The authors would like to thank Vaisala Inc. for providing the NLDN information.

\section{References}

Anderson, R. B., and A. J. Eriksson (1980), Lightning parameters for engineering applications, Electra, 69, 65-102.

Berger, K., and E. Vogelsanger (1966), Photographische blitzuntersuchungen der jahre 1955-1965 auf dem Monte San Salvatore, Bull. Schweiz. Elektrotech. Ver., 57, 599-620.

Berger, K., and E. Vogelsanger (1969), New results of lightning observations, in Planetary Electrodynamics, edited by S. C. Coroniti and J. Hughes, pp. 489-510, Gordon and Breach, New York.

Berger, K., R. B. Anderson, and H. Kroninger (1975), Parameters of lightning flashes, Electra, 80, 23-37.

Chen, M., N. Takagi, T. Watanabe, D. Wang, Z. I. Kawasaki, and X. Liu (1999), Spatial and temporal properties of optical radiation produced by stepped leaders, J. Geophys. Res., 104, 27,573-27,584.

Chen, M., T. Watanabe, N. Takagi, Y. Du, D. Wang, and X. Liu (2003), Simultaneous observations of optical and electrical signals in altitudetriggered negative lightning flashes, J. Geophys. Res., 108(D8), 4240, doi:10.1029/2002JD002676.

Cooray, V., and S. Lundquist (1982), On the characteristics of some radiation fields from lightning and their possible origin in possible origin in ground flashes, J. Geophys. Res., 87(C13), 11,203-11,214.

Cooray, V., R. Montano, and V. Rakov (2004), A model to represent negative and positive lightning first strokes with connecting leaders, J. Electrost., $60,97-109$.

Cummins, K. L., M. J. Murphy, E. A. Bardo, W. L. Hiscox, R. B. Pyle, and A. E. Pifer (1998), A combined TOA/MDF technology upgrade of the U.S. National Lightning Detection Network, J. Geophys. Res., 103(D8), 9035-9044.
Cummins, K. L., J. A. Cramer, C. Biagi, E. P. Krider, J. Jerauld, M. A. Uman, and V. A. Rakov (2006), The U.S. National Lightning Detection Network: Post-upgrade status, in Proceedings of the Second Conference on Meteorological Applications of Lightning Data, 86th AMS Annual Meeting, Am. Meteorol. Soc., Boston, Mass.

Eriksson, A. J. (1978), Lightning and tall structures, Trans. S. Afr. Inst. Electr. Eng., 69, 238-252.

Golde, R. H. (1967), The lightning conductor, J. Franklin Inst., 283, 451477.

Gorin, B. N. (1985), Mathematical modeling of the lightning return stroke, Elektrichestvo, 4, 10-16.

Hagenguth, J. H. (1947), Photographic study of lightning, Trans. Am. Inst. Electr. Eng., 66, 577-585.

Idone, V. P., A. B. Saljoughy, R. W. Henderson, P. K. Moore, and R. B. Pyle (1993), A reexamination of the peak current calibration of the National Lightning Detection Network, J. Geophys. Res., 98, 18,323-18,332.

Jerauld, J., V. A. Rakov, M. A. Uman, D. E. Crawford, B. A. DeCarlo, D. M. Jordan, K. J. Rambo, and G. H. Schnetzer (2003), Multiplestation measurements of electric and magnetic fields due to natural lightning, in Proc. Int. Conf. on Lightning and Static Elec. (ICOLSE), Blackpool, United Kingdom.

Jerauld, J., V. A. Rakov, M. A. Uman, K. J. Rambo, and D. M. Jordan (2005), An evaluation of the performance characteristics of the U.S. National Lightning Detection Network using triggered lightning in Florida, J. Geophys. Res., 110, D19106, doi:10.1029/2005JD005924.

Kodali, V., V. A. Rakov, M. A. Uman, K. J. Rambo, G. H. Schnetzer, J. Schoene, and J. Jerauld (2005), Triggered-lightning properties inferred from measured currents and very close electric fields, Atmos. Res., 76, 355-376, doi:10.1016/j.atmosres.2004.11.036.

Krehbiel, P. R. (1981), An analysis of the electric field change produced by lightning, Ph.D. thesis, University of Manchester Institute of Science and Technology, Manchester, England.

Krider, E. P., and C. G. Ladd (1975), Upward streamers in lightning discharges to mountainous terrain, Weather, 30, 77-81.

Lalande, P., A. Bondiou-Clergerie, P. Laroche, A. Eybert-Berard, J. P. Berlandis, B. Bador, A. Bonamy, M. A. Uman, and V. A. Rakov (1998), Leader properties determined with triggered lightning techniques, J. Geophys. Res., 103(D12), 14,109-14,115.

Lin, Y. T., M. A. Uman, J. A. Tiller, R. D. Brantley, W. H. Beasley, E. P. Krider, and C. D. Weidman (1979), Characterization of lightning return stroke electric and magnetic fields from simultaneous two-station measurements, J. Geophys. Res., 84, 6307-6314.

Master, M. J., M. A. Uman, W. H. Beasley, and M. Darveniza (1984), Lightning induced voltages on power lines: Experiment, IEEE Trans. Power Appar. Syst., 103, 2519-2529.

McEachron, K. B. (1939), Lightning to the empire state building, J. Franklin Inst., 227, 149-217.

Miki, M., et al. (2005), Initial stage in lightning initiated from tall objects and in rocket-triggered lightning, J. Geophys. Res., 110, D02109, doi:10.1029/2003JD004474.

Miyazaki, S., and M. Ishii (2006), Reproduction of time derivative of electromagnetic field associated with rocket-triggered lightning in submicrosecond range, J. Geophys. Res., 111, D22203, doi:10.1029/ 2005JD006471.

Murray, N. D., E. P. Krider, and J. C. Willett (2005), Multiple pulses in $\mathrm{dE} / \mathrm{dt}$ and the fine structure of $\mathrm{E}$ during the onset of first return strokes in cloud-to-ocean lightning, Atmos. Res., 76, 455-480.

Olsen, R. C., D. M. Jordan, V. A. Rakov, M. A. Uman, and N. Grimes (2004), Observed one-dimensional return stroke propagation speeds in the bottom $170 \mathrm{~m}$ of a rocket-triggered lightning channel, Geophys. Res. Lett., 31, L16107, doi:10.1029/2004GL020187.

Olsen, R. C., V. A. Rakov, D. M. Jordan, J. Jerauld, M. A. Uman, and K. J. Rambo (2006), Leader/return-stroke-like processes in the initial stage of rocket-triggered lightning, J. Geophys. Res., 111, D13202, doi:10.1029/2005JD006790.

Rakov, V. A., and A. A. Dulzon (1991), A modified transmission line model for lightning return stroke field calculations, in Proc. 9th Int. Sym. on Electromagnetic Compatibility, pp. 229-235, ETH ZentrumIKT, Zurich, Switzerland, paper 44H1.

Rakov, V. A., and M. A. Uman (1990), Some properties of negative cloudto-ground lightning flashes versus stroke order, J. Geophys. Res., 95, $5447-5453$.

Rakov, V. A., and M. A. Uman (1998), Review and evaluation of lightning return stroke models including some aspects of their application, IEEE Trans. Electromagn. Compat., 40(4), 403-426.

Rakov, V. A., and M. A. Uman (2003), Lightning: Physics and Effects, Cambridge Univ. Press, New York.

Rakov, V. A., M. A. Uman, and R. Thottappillil (1994), Review of lightning properties from electric field and TV observations, J. Geophys. Res., 99(D5), 10,745-10,750. 
Rakov, V. A., et al. (1998), New insights into lightning processes gained from triggered-lightning experiments in Florida and Alabama, J. Geophys. Res., 103(D12), 14,117-14,130.

Rakov, V. A., D. E. Crawford, V. Kodali, V. P. Idone, M. A. Uman, G. H. Schnetzer, and K. J. Rambo (2003), Cutoff and reestablishment of current in rocket-triggered lightning, J. Geophys. Res., 108(D23), 4747 , doi:10.1029/2003JD003694.

Schoene, J., M. A. Uman, V. A. Rakov, K. J. Rambo, J. Jerauld, and G. H. Schnetzer (2003), Test of the transmission line model and traveling current source model with triggered lightning return strokes at very close range, J. Geophys. Res., 108(D23), 4737, doi:10.1029/2003JD003683.

Thomson, E. M. (1985), A theoretical study of electrostatic field wave shapes from lightning leaders, J. Geophys. Res., 90, 8125-8135.

Thottappillil, R., and M. A. Uman (1993), Comparison of return stroke models, J. Geophys. Res., 98(D12), 22,903-22,914.

Uman, M. A., and D. K. McLain (1969), Magnetic field of the lightning return stroke, J. Geophys. Res., 74, 6899-6910.

Uman, M. A., D. K. McLain, and E. P. Krider (1975), The electromagnetic radiation from a finite antenna, Am. J. Phys., 43, 33-38.

Visacro, S., A. Soares Jr., M. A. O. Schroeder, L. C. Cherchiglia, and V. J. de Sousa (2004), Statistical analysis of lightning current parameters: measurements at Morro do Cachimbo Station, J. Geophys. Res., 109, D01105, doi:10.1029/2003JD003662.

Wagner, C. F. (1960), Determination of the wave front of lightning stroke currents from field measurements, IEEE Trans. Power Appar. Syst., 79 $581-589$

Wang, D., V. A. Rakov, M. A. Uman, N. Takagi, T. Watanabe, D. E. Crawford, K. J. Rambo, G. H. Schnetzer, R. J. Fisher, and Z. I. Kawasaki (1999a), Attachment process in rocket-triggered lightning strokes, J. Geophys. Res., 104, 2143-2150.

Wang, D., N. Takagi, T. Watanabe, V. A. Rakov, and M. A. Uman (1999b), Observed leader and return-stroke propagation characteristics in the bottom $400 \mathrm{~m}$ of the rocket triggered lightning channel, J. Geophys. Res., 104, 14,369-14,376.

Wang, D., M. Chen, N. Takagi, and T. Watanabe (2001), Correlated submicrosecond -field and high-speed image of the natural lightning attachment process, in Proc. Int. Conf. Lightning and Static Elec. (ICOLSE), Society of Automotive Engineers (SAE), Seattle, Washington.

Weidman, C. D., and E. P. Krider (1978), The fine structure of lightning return stroke wave forms, J. Geophys. Res., 83(C12), 6239-6247.

Weidman, C. D., and E. P. Krider (1980), Submicrosecond risetimes in lightning return-stroke fields, Geophys. Res. Lett., 7, 955-958.

Willett, J. C., and E. P. Krider (2000), Risetimes of impulsive high-current processes in cloud-to-ground lightning, IEEE Trans. Antennas Propag., 48(9), $1442-1450$

Willett, J. C., V. P. Idone, R. E. Orville, C. Leteinturier, A. Eybert-Berard, L. Barret, and E. P. Krider (1988), An experimental test of the "transmission-line model" of electromagnetic radiation from triggered lightning return strokes, J. Geophys. Res., 93(D4), 3867-3878.

Willett, J. C., J. C. Bailey, V. P. Idone, A. Eybert-Berard, and L. Barret (1989a), Submicrosecond intercomparison of radiation fields and currents in triggered lightning return strokes based on the transmission-line model, J. Geophys. Res., 94(D11), 13,275-13,286.

Yokoyama, S., K. Miyake, T. Suzuki, and S. Kanao (1990), Winter lightning on Japan Sea coast-Development of measuring system on progressing feature of lightning discharge, IEEE Trans. Power Deliv., 5, 1418 1425 .

J. Jerauld, V. A. Rakov, K. J. Rambo, G. H. Schnetzer, and M. A. Uman, Department of Electrical and Computer Engineering, University of Florida, P.O. Box 116200, Gainesville, FL 32611-6130, USA. (uman@ece.ufl.edu) 